\title{
Monitoring Banking System Connectedness with Big Data
}

\author{
Galina Hale \\ Jose A. Lopez \\ Federal Reserve Bank of San Francisco \\ April 2018 \\ Working Paper 2018-01 \\ http://www.frbsf.org/economic-research/publications/working-papers/2018/01/
}

\section{Suggested citation:}

Hale, Galina, Jose A. Lopez. 2018. "Monitoring Banking System Connectedness with Big Data” Federal Reserve Bank of San Francisco Working Paper 2018-01.

https://doi.org/10.24148/wp2018-01

The views in this paper are solely the responsibility of the authors and should not be interpreted as reflecting the views of the Federal Reserve Bank of San Francisco or the Board of Governors of the Federal Reserve System. 


\title{
Monitoring Banking System Connectedness with Big Data
}

\author{
Galina Hale \\ Jose A. Lopez \\ Federal Reserve Bank of San Francisco*
}

April 23, 2018

\begin{abstract}
The need to monitor aggregate financial stability was made clear during the global financial crisis of 2008-2009, and, of course, the need to monitor individual financial firms from a microprudential standpoint remains. However, linkages between financial firms cannot be observed or measured easily. In this paper, we propose a procedure that generates measures of connectedness between individual firms and for the system as a whole based on information observed only at the firm level; i.e., no explicit linkages are observed. We show how bank outcome variables of interest can be decomposed, including with mixed-frequency models, for how network analysis to measure connectedness across firms. We construct two such measures: one based on a decomposition of bank stock returns, the other based on a decomposition of their quarterly return on assets. Network analysis of these decompositions produces measures that could be of use in financial stability monitoring as well as the analysis of individual firms' linkages.
\end{abstract}

JEL codes: C32, G21, G28

Keywords: financial stability, bank supervision, network centrality, systemic connectedness

\footnotetext{
${ }^{*}$ The views in this paper are solely the responsibility of the authors and should not be interpreted as reflecting the views of the Federal Reserve Bank of San Francisco or the Board of Governors of the Federal Reserve System. We thank Tesia Chuderewicz and Shannon Sledz for their excellent research assistance. We benefitted from comments from Fred Furlong, Eric Ghysels, Linda Goldberg, Eric Heitfield, Anna Kovner, James Vickery, two anonymous referees as well as seminar participants at the Federal Reserve Banks of Dallas and New York and colleagues within the Federal Reserve System.
} 


\section{Introduction}

In recent years, the economic literature in several fields has shown increased interest in measuring and understanding how various economic agents are connected with each other. The literature on social, trade, industrial, and financial networks has blossomed. Yet, in some fields, and especially in finance, measuring connectedness between financial firms remains challenging since the data needed to gauge these linkages are not observed readily or are not available at the appropriate level of granularity. A key insight into this challenge was provided by Diebold and Yilmaz (2014) in that they chose to gauge financial firm connectedness using their stock returns as the input data. They analyze the network implied by their stock return volatility, which neatly avoids data availability challenges while still capturing the aggregate and idiosyncratic effects of the firms' interconnectedness 1

The goal of this paper is to develop a procedure that can be used to construct firm-level connectedness measures that rely on as much of the available data for U.S. bank holding companies (BHCs), have a transparent interpretation, and exhibit desired statistical properties. While we frame our discussion in terms of measuring the connectedness of these financial firms for various purposes (with an emphasis on bank supervision and financial stability monitoring), the proposed approach can be applied readily to other networks of interest, such as industrial sectors. Our procedure generates distinct measures of overall system connectedness and indicators of how individual entities are both connected to each other and to the system as a whole. The procedure relies on data that is available at the entity level, and no direct information on actual linkages between entities is available.

From the perspective of bank supervision, the global financial crisis of 2008-2009 and the subsequent regulatory response have brought forth the importance of measuring and monitoring financial stability and connectedness within (and across) national banking systems. ${ }^{2}$ A key design element

\footnotetext{
${ }^{1}$ The recent network literature has proposed techniques that transform various forms of data into connectedness measures. For example, Demirer et al. (2017) also use stock market returns to characterize the high-dimensional network linking the largest global banks over the period from 2003 to 2014. In contrast, Hale et al. (2016) use interbank lending exposures to measure the transmission of financial shocks across borders through international bank connections.

${ }^{2}$ Researchers have proposed a wide variety of financial stability measures, such as CoVaR (Adrian and Brunnermeir 2016); see Bisias et al. (2012) for a survey as well as Brave and Lopez (2017) for analysis of specific measures. Connectedness has also been studied via the interbank lending market (Afonso and Lagos, 2015).
} 
in such monitoring efforts is in selecting explanatory variables useful for the identification of both macroprudential (or systemic) and microprudential (or firm-specific) concerns. Theoretically, all data sources on financial firms are of interest for these activities, but in reality, they all have particular strengths and weaknesses. For example, focusing on data frequency, we have extensive quarterly balance sheet data, which provide the most comprehensive and up-to-date summaries of firm conditions (i.e., asset quality and income). However, these data are available with time lags and likely too infrequently for use in responding to fast-moving events. At the other extreme, daily market data is timely and aggregate much current information, but their volatility and tendency to initially overreact to incoming news limits their usefulness for supervisory monitoring purposes.

Bank supervisors have faced related challenges regarding these data sources for some time; for example, see the long span of literature from Meyer and Pifer (1970) to Balasubramnian and Palvia (2018). To date, however, these efforts have been targeted to microprudential supervisory purposes. Our goal is to develop empirical measures that would be useful for macroprudential monitoring as well. While many measures of financial stability have been proposed, no one source of banking data provides a clear measure of interconnectedness for both purposes. In our work, we pay specific attention to identifying connectedness that arises from common factors affecting all network firms separately from connectedness that is driven more by the spillover of idiosyncratic shocks.

Our procedure consists of two steps: the decomposition of a $\mathrm{BHC}$ outcome variable into components of interest, and the network analysis of these components. The decomposition allows us to extract common factors that affect all firms within the network and, more importantly, identify idiosyncratic shocks that include any remaining connections between the firms. We propose a number of approaches on how this decomposition, focusing on dealing with mixed frequency data. The network analysis can then be applied to any component resulting from the decomposition, with a particular emphasis on the idiosyncratic terms.

For our proposed measures, we examine bank holding company (BHC) data to study how the largest U.S. banks were interlinked during the period from 2005 through 2015. The two outcome measures we analyze are weekly stock returns and quarterly returns on assets (ROA). We decompose these measures into fitted values and residuals using various regression techniques. We decompose stock returns using OLS into what we refer to as common and idiosyncratic components using a 
simple CAPM regression. We decompose ROA into what we refer to as observed and unobserved components, including both market and firms-specific factors, using a "kitchen-sink" approach with mixed-frequency data.

We proceed in our network analysis by constructing connectedness measures for idiosyncratic stock return components using the vector auto-regression (VAR) approach proposed by Diebold and Yilmaz (2009). However, we use a simple correlation approach to construct connectedness measures for the observed and unobserved components of ROA since there are insufficient quarterly observations for VAR estimation. Thus, the measures we construct span quite well the modalities we describe in our procedure. We provide proof of concept for the resulting measures by comparing them to other measures of interconnectedness used in the literature, interpreting their dynamics around crisis times, and comparing them to each other.

To be clear, we are not proposing a new econometric methodology. Our contribution is to demonstrate how recently developed methodologies can be used to produce useful measures of connectedness from large amount of available data available at mixed frequencies. For the two steps of our procedure, we discuss a variety of options available depending on the question of interest, outcome measures developed, and data constraints. The main innovation of our procedure is that it allows us to separately analyze connectedness resulting from observable vs. unobservable factors or from common vs. idiosyncratic components of the outcome variables of interest. As our example of large banks' connectedness demonstrate, our procedure produces measures that have intuitive dynamics and contain additional information relative to other existing measures. Moreover, they have desired statistical properties of infrequent changes in bank rankings and smooth dynamics. Interestingly, both stock-market-based and ROA-based measures exhibit substantial growth over the last two years of our sample, while none of the relevant raw series and other available measures of banking system risk show such an increase.

We begin by describing our procedure in Part 2. In part 3 we present implementation of the procedure including data description, as well as construction, description, and analysis of the measures of systemic connectedness of the U.S. banking system we construct. Summary and conclusions are in Part 4. 


\section{Methodology for variable decomposition and network analysis}

Our implementation procedure consists of two steps. The first step is designed to decompose the outcome measure into the desired components, and the second step is constructing network connectedness measures based on these components. In this section, we discuss our procedure in general terms, and we discuss our specific implementation exercises in Section 3.

\subsection{Step 1: Variable Decomposition}

Our analysis uses individual firm performance measures - such as weekly BHC stock returns or quarterly BHC returns on assets - as initial data inputs, as per Diebold and Yilmaz (2009) and related studies. However, to better examine both the macroprudential and microprudential aspects of financial system connectedness, we propose standard decompositions that highlight specific elements of the data.

A common criticism of connectedness measures based on firm stock returns is that they are dominated by a common component. Within the classic CAPM framework, this caveat is clearly expressed as

$$
y_{i t}=\beta_{i} r_{m t}+\varepsilon_{i t}
$$

where $y_{i t}$ is a firm-specific return and $r_{m t}$ is the return on a market index. This equation can be applied to each $i$ to obtain firm-specific $\beta_{i}$ coefficient estimates. The term $\beta_{i} r_{m t}$ represents the effect of the common market return, and it can be removed to examine the idiosyncratic firm components (or the $\varepsilon_{i t}$ residuals). Thus, the first type of decomposition we propose is into common and idiosyncratic components.

The second decomposition we consider is designed to separate out all explainable (or observable) variation in $y_{i t}$ relative to what cannot be explained with available data (i.e., the "unobservable" component). In notational form, this decomposition is

$$
y_{i t}=Z_{t}^{\prime} \beta_{i}+X_{i t}^{\prime} \gamma_{i}+\varepsilon_{i t}
$$

where $Z_{t}$ is a set of common variables (such as $r_{m t}$ above) and $X_{i t}$ represents a vector of all 
explanatory variables available to the researcher. The fitted values, which are a linear combination of the first two terms, can be labeled as the observable component, and the residual $\varepsilon_{i t}$ term is the unobservable component. This approach allows us to introduce all available information in a "kitchen-sink" modeling approach

To conduct these decompositions for our analysis of banking system connectedness, we estimate individual firm regressions, using OLS techniques if all of the variables are available at the same frequency ${ }^{3}$ This, however, is not commonly the case.

For this reason, Ghysels et al. (2002) propose a mixed-data sampling model based on distributed lags, commonly known as a MIDAS regression 4 In that framework, higher-frequency explanatory variables can be included as distributed lags, with a decay parameter estimated either non-parametrically as an unrestricted MIDAS model (i.e., U-MIDAS) as proposed by Foroni et al. (2013), or assumed to have a decay of a specific functional form for which parameters are estimated. For example, if $y_{i t}$ is observed quarterly with $t$ indicating a specific calendar date and a subset of $X_{i t} \in\left[X_{i t}^{q}, X_{i t}^{w}\right]$ where the latter is observed weekly, the MIDAS regression can be specified as

$$
y_{i t}=X_{i t}^{q^{\prime}} \beta_{i}+\left(\sum_{s=1}^{S} X_{i(t-7 s)}^{w^{\prime}} \delta_{i s}\right)^{\prime} \gamma_{i}+\varepsilon_{i t},
$$

where $s$ is the counter for the weeks in the quarter and $S=13$. Again, this equation is intended to be estimated for each $i$ separately.

An alternative estimation approach is a mixed frequency factor model estimated in state-space form using the Kalman filter $(\mathrm{KF}) \cdot 5^{5}$ An advantage of this approach is not requiring any parametric assumptions; that is, one can simply cast the mixed-frequency data into state-space form and estimate the model coefficients. Continuing the notation above, suppose the underlying state process that is driving $y_{i t}$ is autoregressive and can be represented with vector $\alpha_{i t}$ with transition equation

$$
\alpha_{i t+1}=\Phi_{i} \alpha_{i t}+\Psi_{i} \omega_{i t}
$$

\footnotetext{
${ }^{3}$ Note that we also assume all variables are stationary in our analysis for simplicity.

${ }^{4}$ Asymptotic and other statistical properties of the estimator are reported in Andreou et al. (2010).

${ }^{5}$ See Ghysels et al. (2009) for a comparison and relative merits of the these two estimation methods.
} 
where $\omega_{i t}$ is a transition shock. The measurement equation is then

$$
\tilde{y}_{i t}=A \alpha_{i t}+B \tilde{x}_{i t}+\varepsilon_{i t}
$$

where $\tilde{y}_{i t}$ is a vector that includes outcome variable $y_{i t}$ as well as any elements of $X_{i t}$ that are deemed endogenous to the state, while $\tilde{x}_{i t}$ is a vector of exogenous variables. $\varepsilon_{i t}$ is a measurement shock. Aruoba et al. (2009) demonstrate that the estimation process is valid in the cases of missing data, including data missing due to mixed frequencies. Bai et al. (2013) develop an alternative approach using a periodic steady-state Kalman filter, as described in Assimakis and Adam (2009). In this approach, the measurement equation consists of two parts - one at low frequency, and one at higher frequency that repeats periodically within each low-frequency time period. Bai et al. (2013) show theoretically and with actual data that this approach produces forecasts similar to MIDAS, including in small samples 6

The discussion above does not dwell on how the filtering equation for variable decomposition is selected. The decision might be informed by theory, a specific question that needs to be addressed, as well as the available data. It is important to emphasize that this decision is key for the interpretation of the results. For example, it is unlikely that all common components can be cleanly removed, especially since there are likely to be factors that common to just subsets of the observations. If desired, principle component analysis or dynamic factor models might be used to remove common factors that are not directly observed 7 One has to be cautious using such an approach in the small-scale systems in which idiosyncratic shocks affect system dynamics, because removing common shocks might remove a portion of idiosyncratic ones. In terms of "kitchen-sink" approaches, a variety of model-selection methods are available for determining the best fit.

\subsection{Step 2: Measuring connectedness}

The difficulty in measuring firm connectedness arises from the fact that actual linkages between firms $i$ and $j$ are not commonly observed. Several approaches have been introduced in the literature

\footnotetext{
${ }^{6}$ Real data comparison for macroeconomic variables is conducted by Schorfheide and Song (2009) in the context of mixed-frequency vector auto-regression. A summary of the variety of approaches to estimate mixed-frequency models is also in Foroni and Marcellino (2013).

${ }^{7}$ These approaches are used in relation to measurement of bank linkages in Kapinos and Mitnik (2016) and Kapinos et al. (2017).
} 
using individual firms' stock returns. The goal is to produce a matrix of linkages with all elements ij filled, which can then be used as the adjacency matrix in network analysis. For example, the simplest and most straightforward approach is to compute pairwise correlations for each pair of firms. Another approach is to use a vector autoregression (VAR) model to estimate the effects of firm $i$ on firm $j$ and define connectedness via forecast error variance decomposition or through a generalized impulse response function. VAR, of course, needs to be identified, and Diebold and Yilmaz (2009) propose to identify it with a shrinkage estimator using the elastic net:8

Other approaches to measure the systemic risks of financial firms include conditional valueat-risk (or CoVaR) by (Adrian and Brunnermeir, 2016), Marginal Expected Shortfall (or MES) by (Acharya et al. 2012) and the closely related Systemic Risk (or SRISK) by (Acharya et al. 2010; Brownlees and Engle, 2017), and the Distressed Insurance Premium (or DIP) by (Huang et al., 2009, 2012). Since none of these approaches are able to produce explicit measures of linkages between firms $i$ and $j$, we describe the correlation and the VAR approaches.

Correlation We can construct a matrix of pairwise correlations for the series of interest between firms $i$ and $j$ at a point in time, and we can use rolling windows over the full data sample to create a dynamic network. These correlations can be collected into a correlation matrix, which can be interpreted as adjacency matrix for the network, with two modifications. First, diagonal elements need to be replaced with zeros. Second, negative elements are not meaningful in the adjacency matrix. Thus, depending on the application, they can be replaced either with their absolute values if negative linkages are viewed as important as positive ones (such as, for example, in social networks), or zeros if negative linkages are not as important. If the goal is to measure contagion, one may argue that negative linkages actually provide insurance and reduce contagion, and definitely do not contribute to contagion spread. Thus, for our analysis, it might make sense in systemic risk analysis to replace negative linkages with zeros, which would amount to ignoring any effects of insurance or diversification and thus treating it as a conservative adjustment.

There are two main drawbacks of the correlation approach. First, it is entirely backwardslooking in that observed correlations between past values may not be informative of how correlated they might be going forward. Second, the correlation matrix is symmetric, which means the network

\footnotetext{
${ }^{8}$ This approach is also implemented in Diebold and Yilmaz (2012); Demirer et al. (2017).
} 
described by the resulting adjacency matrix is not directional. Accordingly, we cannot distinguish between a firm's impact on the system and its vulnerability to the system.

VAR The VAR approach addresses both main drawbacks of the correlation approach. First, by estimating a VAR, we can forecast future values of the outcome measure, compute forecast errors, and decompose the error variance as a measure of linkages. While the estimation still relies on past data, at least this approach has a forecast component that makes it predictive and not strictly backward-looking. Second, variance decomposition matrix is not symmetric, allowing us to construct a directional network of linkages and thus measure firm impact and vulnerability separately. Given that components of the variance decomposition matrix are by definition between zero and one, the matrix of the variance decomposition can be used directly as adjacency matrix upon removal of the diagonal.

Upon constructing the adjacency matrix $A$ using one of the methods described above, we construct measures of system connectedness, such as the network density $(D)$ measure, and "systemic importance" measures for each institution, such as the degree centrality $(d c)$ for directed and undirected networks. Formally, these measures are defined as follows:

$$
\begin{gathered}
D=\frac{2 \sum_{i} \sum_{j \neq i} a_{i j}}{N(N-1)}, \\
d c_{i}=\sum_{j \neq i} a_{i j},
\end{gathered}
$$

where $a_{i j}$ is an element of $A$, and $N$ is the number of firms. The network density measure is intuitively the average value of the off-diagonal cells of the matrix, such that a sparse matrix has a low $D$ value and a highly-populated matrix has a high $D$ value. The degree centrality measure similarly adds the values across the row for firm $i$, measuring the size of the firm's connectedness within the system. For interpretation, in case of correlation approach, it might be useful to divide the $d c_{i}$ measure by $N-1$ to obtain average systemic importance of a given firm that is between 0 and 1 by construction.

A directed (or asymmetric) network allows us to distinguish directional degree centrality: outdegree $\left(o d c_{i}\right)$ and in-degree $\left(i d c_{i}\right)$, which can be interpreted, respectively, as the impact of firm $i$ on 
the rest of the system and the vulnerability of firm $i$ to shocks coming from the rest of the system. In notation,

$$
\begin{aligned}
& o d c_{i}=\sum_{j \neq i} a_{i j}, \\
& i d c_{i}=\sum_{j \neq i} a_{j i},
\end{aligned}
$$

As before, $o d c_{i}$ is a row sum measure, but $i d c_{i}$ is a column sun measure. Note that the odc impact measure need not equal the $i d c_{i}$ vulnerability measure, because the contribution of $i$ to $j$ 's forecast error variance need not be the same as the contribution of $j$ to $i$ 's forecast error variance.

If the dynamics of a network measure is of interest, these calculations can be repeated for rolling windows of the outcome measure decomposition. Note that by construction, the $D$ network density measure is bounded to the unit interval, regardless of how the linkages are computed. Similarly, the $i d c_{i}$ measure remains within the unit interval since it measures the total share of forecast error variance for firm $i$ that is explained by all other firms. In contrast, the $d c_{i}$ and $o d c_{i}$ measures can sum to more than one.

\section{Implementation}

Having described our procedure, we now turn to the concrete example of its implementation. Our example is measuring connectedness and systemic importance in the network of large banks. We first describe our data, then demonstrate an application with two different outcome measures: stock returns, which we measure weekly, and returns on assets (ROA), which are available quarterly.

With stock returns which can be measured at any frequency, we don't have a mixed frequency problem, and therefore employ simple linear regression to obtain our decomposition. Here we focus on common and idiosyncratic components interpretation of decomposition and estimate an augmented CAPM regression with five Fama-French factors (French and Fama, 1992) to separate market factors from idiosyncratic ones. With the strong common component, we proceed with the network analysis of the residual from this decomposition, the idiosyncratic component.

With ROA, which is available quarterly, we have explanatory variables that we would like to include in the decomposition that can be measured at higher frequency. Thus, we employ MIDAS 
approach to decompose ROA 9 Here we employ a kitchen-sink approach, interpreting decomposition as resulting in observed and unobserved components of the ROA. We proceed to analyze both the observed and the unobserved components.

\subsection{Data}

Bank supervision is a critical component of monitoring and maintaining the safety and soundness of the U.S. banking and financial system. Dating back to the creation of the Office of the Comptroller of the Currency (OCC) in 1864, bank examiners have collected data on-site and through reporting forms to assess compliance with federal banking regulations (White, 2011). Starting in 1869, balance sheet data collection became more standardized with the development of the "call" report of condition, which are now more commonly known as the Call Reports. After the Bank Holding Company Act of 1956, the Federal Reserve began collecting consolidated BHC data, with the Y9 consolidated reporting forms starting in 1978. All of this data, in conjunction with on-site examinations and other supervisory work, assists in the creation of supervisory bank ratings, which are known as CAMELS for commercial banks and RFI/C(D) ratings for BHCs. Statistical models that summarize supervisory information and correlate it with supervisory outcomes, such as rating changes and bank failures, date back to the mid-1970s and are in wide use currently (King et al. 2006).

In addition to supervisory data, market-based data is available for analysis on the largest BHCs. Pettway and Sinkey (1980) proposed using BHC stock returns for monitoring their financial conditions. Krainer and Lopez $(2004,2008)$ provide evidence using ordered logit models that both supervisory and market-based data provide leading indicators of changes in BHC supervisory ratings. Berger et al. (2000) report similar findings, but highlight that supervisory ratings are generally less accurate than market-based indicators in predicting future changes in bank performance, except when these assessments occurred just after a recent on-site bank examination. All of these efforts have focused on the microprudential goals of monitoring bank-level safety and soundness as well as allocating resource to do so. Since the financial crisis, macroprudential concerns have arisen and been partly addresses with stress-testing of the largest BHCs (Hirtle and Lehneart, 2015). Our

\footnotetext{
${ }^{9}$ We decided in favor of MIDAS over state-space approach because of the short time span for our data analysis.
} 
efforts here work with roughly the same set of firms to derive macroprudential summary measures of banking system vulnerability and microprudential measures of firms' systemic importance.

We focus on the 27 large U.S. BHCs that have been subject to the Federal Reserve's stresstesting and have data available from 2002 to 2017, listed in Table 1. This choice of a balanced panel is intentional to allow for the network modeling. This sample includes largest, systemically important firms that jointly account for over $75 \%$ of U.S. banking assets. We use various data sources in our analysis, which are divided into balance sheet variables and market-based variables. Our main market-based data is the daily stock returns of the sample, BHCs, which we aggregate to the quarterly frequency. Note that we do not merger-adjust these returns, even in light of the large and significant BHC mergers that occurred during 2008 and 2009. Our rationale here is to focus on the specific firms involved in the Federal Reserve's stress-testing program and their network connectedness. Finally, we use S\&P 500 stock market returns at the weekly frequency, effective federal funds rate as reported by the Federal Reserve, as well as five market-wide Fama-French factors from Kenneth French.

We collect consolidated balance sheet data for the sample BHCs from the Y9-C reporting form, which is made publicly available on a quarterly basis 10 . From this source, we use firm's total assets, income, as well as non-performing loans (NPLs).

\subsection{Measure 1: Connectedness based on stock returns}

Our first example is interconnectedness of BHC's stock returns. These are available at any frequency, but we are not necessarily interested in intraday and day-to-day fluctuations, for this reason we choose weekly returns, but computing log change in stock prices from Friday close to Friday close. Existing measures of stock-return-based interconnectedness are frequency criticized for having a larger common component. We can address this criticism using our decomposition into common and idiosyncratic components. For each bank $i$, we will estimate an augmented CAPM regression as follows$$
r_{i t}=\alpha_{i}+\beta_{1 i} r_{t}^{S P}+\beta_{2 i} r_{t}^{F F}+\beta_{3 i} S M B_{t}+\beta_{4 i} H M L_{t}+\beta_{5 i} R M W_{t}+\beta_{6 i} C M A_{t}+\varepsilon_{i t},
$$

${ }^{10}$ https://www.federalreserve.gov/apps/reportforms/reportdetail.aspx?sOoYJ+5BzDal8cbqnRxZRg== 
where $r_{i t}$ is the weekly stock return for firm $i ; r^{S P}$ is a weekly return on S\&P 500, $r^{F F}$ is federal funds rate, while the rest of the controls are market-wide Fama French factors. To allow for $\beta$ s to vary over time, we estimate this regression for a 3-year windows from 2002 through 2017, which we roll forward quarterly.

For almost all banks all of the coefficients estimated are of expected sign and statistically significant. Figure 1 shows raw returns, fitted, and residual values for Wells Fargo, as an example, since April 2016. We can see that both common and idiosyncratic factors play an important role in the dynamics of this bank's stock returns. The share of variance explained by the market factors (regression $R^{2}$ ) for the last rolling window is reported for all banks in Figure 2. We can see that it varies from 30-50\% for foreign and processing banks to as high as $80 \%$ for large and regional banks. Coefficients for each rolling window and each bank on all the variables included in the regression are reported as time series in Appendix figure A1.

Given that the fitted values only vary across banks because of differences in $\beta$ s, we focus on the residuals for the analysis of connectedness. That is, the idiosyncratic component. It should be made clear here, that the term "idiosyncratic" is used vaguely in this case, given that there might be banking-sector-specific common factors that will be manifested as connectedness of the residuals. There are two reasons we choose not to remove such factors in this specific example. First is technical - given that we are dealing with a network of only 27 institutions, removing common factors by extracting principle components or including sector stock index in the regression has a risk of removing truly idiosyncratic component. Second, from the regulatory point of view, correlated response of all institutions to the same shock is as relevant as a truly idiosyncratic contagion from one institution to another.

To construct connectedness of the idiosyncratic component of stock returns at weekly frequency, we estimate a VAR using elastic net shrinkage estimator. A similar implementation is conducted by Demirer et al. (2017) for 100 largest global banks. Following similar methodology, we measure connectedness as variance decomposition of forecast one-quarter-ahead error ${ }^{11}$ To construct dynamic networks, we estimate the VAR for the same 3-year windows rolling quarterly, as we used for the regression decomposition.

\footnotetext{
${ }^{11}$ One alternative is to use impulse response functions, as in Grant and Yung (2017).
} 
The results for the last rolling window ending in December 2017 are reported as an adjacency matrix in Figure 3. We can observe that the most connected pair are Credit Suisse and Deutsche Bank, while the most connected cluster is Credit Suisse, Deutsche Bank, BBVA, and Barclays. This makes sense, because all these are foreign banks and have the largest idiosyncratic component that likely loads on a common European factor. Toronto-Dominion bank, on the other hand, is the least connected to the rest of the system. Time series of individual bank impact and vulnerability measures for the four largest banks are shown in Appendix Figure A2.

The dynamics of the network are quarterly, because we roll the estimation window quarterly. Overall density is presented in Figure 4, where we compare density of the network of the idiosyncratic component with that of the raw stock market returns (constructed using the same VAR approach). We can see that the contribution of the common component makes density of raw returns networks very hight throughout the sample. For the idiosyncratic returns we can see much more pronounced dynamics - an increase in network connectedness during the Global Financial crisis that started in the second half of 2007 as well as a pronounced increase in the last two years. This recent increase is most likely reflecting common response of the banking system to actual and expected regulatory changes in the last couple of years.

This connectedness is not the same for all banks - Figures 5 and 6 shows measures of impact and vulnerability, respectively, by bank business group 12 We find that during the global financial crisis the increased connectedness was limited to the largest four banks (Bank of America, Wells Fargo, Citigroup, and JP Morgan), and regional banks. Connectedness of other banking groups reached the level similar to that of four largest banks in 2009. This makes sense, because this is exactly when regulatory treatment of investment banks, processing banks, and foreign banks' affiliates was made similar to that of the largest four banks. In recent years, the impact of investment banks seems smaller than that of other groups, while vulnerability is lowest for foreign banks.

\footnotetext{
${ }^{12}$ Remember that impact and vulnerability here are defined narrowly as outdegree and indegree, respectively. Big4 banks are BAC, C, JPM, WFC. Processing banks are BK, NTRS, STT. Foreign banks are BBVA, BCS, CS, DB, TD. Regional banks are BBT, CMA, FITB, HBAN, KEY, MTB, PNC, RF, STI, USB, ZION.
} 


\subsection{Comparing to other market-based measures}

To see whether our approach yields estimates that are both reasonable and not spanned by existing measures, we compare our measure to other stock-return-based measures commonly used in the literature. Figure 7 plots standardized and normalized versions of our measure as well as averages across banks of the three measures: conditional value-at-risk or CoVaR Adrian and Brunnermeir, 2016) for each firm $i$, Systemic Risk or SRISK (Acharya et al., 2010, Brownlees and Engle, 2017), and Distressed Insurance Premium or DIP (Huang et al., 2009, 2012). These measures are commonly available for only 11 out of our 27 banks. Thus, we repeat our entire procedure for the same 11 banks so that we have a consistent comparison. We can see that our measure is a bit less volatile but generally has similar dynamics to other measures until end of 2015, when our measure started to diverge from other market-based measures. Thus, we find that our measure is consistent with others but also provides additional information.

\subsection{Learning from crisis times}

Lehman crisis presents an interesting case study. While all banks performed poorly, and some failed, most of the dynamics of their stock returns are captured by market measures. Some of the developments, however, has been idiosyncratic. For example, only Citigroup and Bank of America received bail-out funds from the Targeted Investment Program at the end of 2008 and early in 2009. At the same time, investment banks Goldman Sachs and Morgan Stanley were converted to Bank Holding Companies which gave them access to the same bailout funds, but with the same regulatory strings attached, as commercial banks.

These development are reflected in our connectedness measure, as shown in Figure 8. We can see that Bank of America and Citigroup had a high impact measure on the rest of the system starting the beginning of the crisis in 2007Q3 and before Lehman collapse in 2008Q3. Thus, one may argue, these were the right banks to be subject to bailout. We can see that following the bailout the banks became less connected, especially by 2009Q3, when they were less connected than other banks. In fact, while connectedness of other banks increased slightly through the crisis period, following the bailout, impact of Bank of America and Citigroup declined, indicating that markets started to view them as being apart from the rest of network. 
Investment banks were designated as BHCs in the second half of 2008. We can see that his lead to substantial increase in their impact relative to the previous period. As we have seen in previous discussion, by 2011 these two banks' connectedness measures were not substantially different than those of the other large banks. In Figure 8 we can see clearly, however, that this convergence started in mid-2009.

\subsection{Measure 2: Connectedness based on ROA}

Our second example is interconnectedness of observed and unobserved components of banks' return on assets (ROA), $R_{i t}$. ROA is measured as a ratio of a bank's quarterly income to the average of bank's assets over last three preceding quarters. As such, $R_{i t}$ is measured at quarterly frequency. We use the kitchen-sink approach to separate observed portio of the ROA for each bank from unobserved, acknowledging that market movements might affect book income. To be clear, the kitchen-sink approach does not imply causal effect of explanatory variables on the outcome variable, we simply are trying to get the best fit regression given the data available. In addition to the same set of market factors we used in the first example, which we continue to measure at weekly frequency, we add a measure of non-performing loans (as a share of assets), $N_{i j}$, which is available quarterly. Because of this data structure, we have to use mixed-frequency approach, which we implement with U-MIDAS, an unrestricted form of MIDAS regression which does not require parametric assumptions 13

After extensive pretesting and observing constraints on data availability, we settled on the following regression equation, for 16 banks, starting 2002, estimated individually for each firm $i$ :

$$
R_{i t}=\alpha_{i}+\beta_{i} N_{i t}+\gamma_{i} \sum_{s=1}^{S}\left(\delta_{1 s i} r_{t}^{K B W}+\delta_{2 s i} r_{t}^{F F}\right)+\varepsilon_{i t},
$$

where $R O A_{i t}$ is the quarterly return on assets for firm $i ; N_{i t}$ is a quarterly ratio of non-performing loans to total assets; $r_{t}^{K B W}$ is the weekly return on a large banks index KBW; $r_{t}^{F F}$ is weekly effective federal funds rate as defined above. We estimate this equation via U-MIDAS for the 16 banks for which we have sufficient balance-sheet data going back to 2012. Due to lower frequency of the dependent variable, we estimate one equation for each bank for the entire time period and

\footnotetext{
${ }^{13}$ We make use of $\mathrm{R}$ code produced by Ghysels et al. (2016) to estimate U-MIDAS.
} 
construct fitted and residual values. Even though this specification is parsimonious, it includes bank-specific, sector-specific, and macroeconomic factors that fit the ROA quite well as shown by $R^{2}$ in Figure 10. Using the example of Wells Fargo, Figure 9 shows the decomposition of the ROA into observed and unobserved components. We can see that the model captures quite well negative returns at the peak of the crisis in 2008Q4, leaving very little to the residual. Most likely, this is due to a combination of market impact via KBW index and bank-specific NPLs. Overall we can see that the volatility of observed and unobserved components of ROA are quite similar. Coefficients on all variables in the regression for all banks are reported in Appendix Figure A3.

Given that regressions include bank-specific factors, we are interested in connectedness of both, fitted values (observed component) and residuals (unobserved component). For this case, given quarterly data and short time frame, we resort to simple correlations as measures of connectedness. To obtain dynamic networks, we construct correlations over 16-quarter rolling windows.

Remember that correlation methods produces a non-directional network, which is why adjacency matrices from the last rolling window reported in Figures 9 and 10 for observed and unobserved components, respectively, are symmetric. Because we are interested in the measure of banking system fragility, only positive correlations are threatening to the system, either as response to common shocks or as contagion arising from idiosyncratic shocks. Negative correlations, instead, would serve as mitigating factors that one can think of diversification or insurance. For this reason, we replace negative correlations with zeros instead of replacing them with absolute values.

We find that observed components are quite highly connected for a number of banks and a negative correlation arises very infrequently. As an example, Figure 11 shows the adjacency matrix for the last rolling window ending 2017Q4. The least connected banks in terms of the observed component are JP Morgan, NTRS, and BBVA. Given that they all face the same sectoral and macroeconomic conditions, this indicates that either the dynamics of their NPLs is quite different of that of other banks, or the response of their returns to sectoral and macroeconomic factors is different from the rest of banks in the network. BBT, Bank of America, and Citibank are, on the other hand, quite highy conected with the rest of the network.

The unobserved components have a number of negative correlations and are generally less connected than observed components. Figure 12 shows the adjacency matrix for the last rolling 
window. Again, JP Morgan, NTRS, and BBVA are the least connected (although unobserved component of BBVA is highly connected with that of Citigroup). Combined with previous finding, this shows that these banks' ROAs have moved differently in the last four years of our data from the rest of the banks in the network. Highly connected unobserved components are apparent for Key Bank and MTB. One can only see a highly-connected cluster in the network: Wells Fargo, PNC, US Bank, and Key Bank. Another cluster consists of CMA, HSBC, and MTB.

Looking at the dynamics of connectedness for the four large banks, as shown in Figures 13 and 14, for observed and unobserved connectedness, respectively. We can see that JP Morgan stands out, with dynamics completely different from three other large banks, for which the dynamics are more or less the same. Interestingly, for the other three large banks we observe an increase in unobserved connectedness in recent year similar to what we observed for the market return-based connectedness, our first measure. This is reassuring, because we applied different methodologies to different variables in every step of our procedure.

This increase in connectedness in the last two years is also visible in the overall density, as shown in Figure 15. We can see that, despite declining or steady connectedness of raw ROAs in recent years, both observed and unobserved components' connectedness is on the rise. While for observed connectedness the level is still about half of what we observed during the crisis, for unobserved connectedness current level is nearly as high as the peak in early 2010. Again, this is a similar pattern to the one resulting from Measure 1, suggesting that some underlying connectedness in bank performance that is not easily measured otherwise, is on the rise.

\subsection{Connectedness between observed and unobserved components}

We would like to discuss one extension to our analysis. So far, we considered each component resulting from our decomposition as completely independent. While it is true that by construction our decomposition yields components that are orthogonal to each other for each individual institution, observed and unobserved components, for example, may be connected across institutions. That is, if we create a $2 N * 2 N$ adjacency matrix of both observed and unobserved components, there might be interesting linkages in the off-diagonal $N * N$ submatrices. These elements are important to measure to assess overall systemic importance of an institution. 
We conduct this exercise for observed and unobserved components of ROA that we computed for our second measure. For these, we compute $32 * 32$ correlation matrix for observed and unobserved components for our 16 banks, using the same 16-quarter rolling window. Because the matrix is symmetric, we only need to analyze one off-diagonal submatrix which we can view as a cluster in the network. Figure 16 shows this submatrix for the last rolling window in our sample. We can see that most correlations are either negative, zero, or very small. Only a handful of correlations stand out - it appears that unobserved component (residuals) for JP Morgan is correlated with the observed component (fitted) for a number of banks and observed component for JP Morgan is correlated with unobserved component for the same set of banks. This tells us that systemic importance of JP Morgan is, in fact, larger than measured by its connectedness in observed and unobserved component networks when viewed separately. We can also note that observed and unobserved components of BBT and NTRS ROAs are highly correlated with each other. Finally, unobserved component with NTRS is correlated with observed components of most other banks in the network.

Figure 17 shows the dynamics of this cluster density (that is, average correlation across all elements of the off-diagonal submatrix, for which we replaced negative numbers with zeros) and compares it with the density of observed and unobserved clusters that we described before. We find, as we expected, that correlations between observe and unobserved components tend to be substantially lower than within observed and across unobserved components across banks. Thus, in our case, analyzing connectedness of observed and unobserved components separately is not a bad approximation.

\section{Summary and conclusions}

In this paper we propose a procedure that allows us to construct systemic connectedness measures on the basis of the data that are only available at individual level, not individual-pair level. We pay particular attention to methods available to extract a common component, including recently developed techniques for the analysis of mixed frequency data. We implement our procedure to construct two measures of U.S. banking system connectedness. 
Bank supervision is an important public policy concern that dates back to at least the 1860s in the United States. While the firm-specific (or microprudential) issues remain as relevant as ever, policymakers have added macroprudential (or systemic) concerns to their supervisory responsibilities since the global financial crisis. Our measures of network density and of firm-specific systemic impact and vulnerability should be of broad usefulness to bank supervisors.

Our methodological proposal consists of two steps that combine several recent developments in network analysis for supervisory use. The first step based on mixed-frequency regression techniques allow us to decompose firm performance measures into a fitted (common or observed) component and a residual (idiosyncratic or unobserved) component. While we use a particular regression specification, other users might choose to select other variables or other specification to achieve a decomposition that suits their purpose and data structure. For bank supervisors, such decomposition provides information when new developments outside of their standard scope of monitoring may be arising and may require additional resources. For this study, we examine weekly BHC stock returns and quarterly ROAs, but other measures — such as credit risk or loan losses — could be similarly analyzed. The isolation of the unobserved component is of particular interest as it reflects factors that are not measured otherwise.

The second step of our procedure is based on network analysis, mainly of the type proposed by Diebold and Yilmaz $(2009,2012,2014)$, as well as simple correlations. We examine several measures of aggregate and firm-specific network connectedness to provide supervisory insights on the current state of banking system stability. There are various measures and analytics available, and we propose the use of a representative set of them; however, we acknowledge that other users or other policy questions might require the use of other measures. We see this flexibility as a strength of our proposed framework.

Finally, we show that measures we construct are meaningful — in terms of comparison with other existing measures and their dynamics around crisis times — and contain additional information relative to other measures. Specifically, both measure we construct, using different variables and approaches at every step of the procedure, show a substantial increase in the last two years of our sample. This increase is absent from any raw data series or other systemic risk measures available for the banking system. 


\section{References}

Acharya, V. V., Engle, R. F., and Rchardson, M. P. (2010). Capital shortfall: A new approach to ranking and regulating systemic risk. American Economic Review: Papers and Proceedings, 102:59-64.

Acharya, V. V., Pedersen, L. H., Philippon, T., and Rchardson, M. P. (2012). Measuring systemic risk. CEPR Working Paper.

Adrian, T. and Brunnermeir, M. K. (2016). CoVaR. American Economic Review, 106(7):1704-41.

Afonso, G. and Lagos, R. (2015). Trade dynamics in the market for federal funds. Econometrica, 83:263-313.

Andreou, E., Ghysels, E., and Kourtellos, A. (2010). Regression models with mixed sampling frequencies. Journal of Econometrics, 158(2):246-61.

Aruoba, S., Diebold, F., and Scotti, C. (2009). Real-time measurement of business conditions. Journal of Business and Economic Statistics, 27(4):417-27.

Assimakis, N. and Adam, M. (2009). Steady state kalman filter for periodic models: A new approach. International Journal of Contemporary Mathematical Sciences, 4:201-18.

Bai, J., Ghysels, E., and Wright, J. H. (2013). State Space Models and MIDAS Regressions. Econometric Reviews, 32(7):779-813.

Balasubramnian, B. and Palvia, A. (2018). Can short sellers inform bank supervision? Journal of Financial Services Research, 53(1):69-98.

Berger, A., Davies, S., and Flannery, M. (2000). Comparing market and supervisory assessments of bank performance: Who knows what when? Journal of Money, Credit, and Banking, 32(3):641667.

Bisias, D., Flood, M., Lo, A., and Val, S. (2012). A survey of systemic risk analytics. Annual Review of Financial Economics, 4:255-296. 
Brave, S. and Lopez, J. (2017). Calibrating macroprudential policy to forecasts of financial stability. Federal Reserve Bank of San Francisco WP 2017-17.

Brownlees, C. and Engle, R. (2017). SRISK: A conditional capital shortfall measure of systemic risk. Review of Financial Studies, 30(1):48-79.

Demirer, M., Diebold, F., Liu, L., and Yilmaz, K. (2017). Estimating global bank network connectedness. National Bureau of Economic Research WP 23140.

Diebold, F. and Yilmaz, K. (2009). Measuring financial asset return and volatility spillovers with application to global equity markets. Economic Journal, 119(534):158-171.

Diebold, F. and Yilmaz, K. (2012). Better to give than to receive: Predictive measurement of volatility spillovers. International Journal of Forecasting, 28(1):57-66.

Foroni, C., Macellion, M., and Schumacher, C. (2013). Unrestriced mixed data sampling (MIDAS): MIDAS regressions with unresticted lag polynomials. Journal of the Royal Statistical Society: Series A (Statistics in Society), 178(1):57-82.

Foroni, C. and Marcellino, M. (2013). A survey of econometric methods for mixed-frequency data. Norges Bank WP 2013/06.

French, K. R. and Fama, E. (1992). The cross-section of expected stock returns. Journal of Finance, $47(2): 427-465$.

Ghysels, E., Kvedaras, V., and Zemlys, V. (2016). Mixed Freqency Data Sampling Regression Models: the R Package midasr. Journal of Statistical Software, 72(4).

Ghysels, E., Santa-Clara, P., and Valkanov, R. (2002). The MIDAS Touch: Mixed Data Sampling Regression Models. Mimeo.

Grant, E. and Yung, J. (2017). The double-edged sword of global integration: Robustness, fragility \& contagion in the international firm network. FRB Dallas Globalization and Monetary Policy Institute Working Paper 313. 
Hale, G., Kapan, T., and Minoiu, C. (2016). Crisis transmission through the global banking network. IMF Working Paper 16/91.

Hirtle, B. and Lehneart, A. (2015). Supervisory stress tests. Annual Review of Financial Economics, $7(1): 339-355$.

Huang, X., Zhou, H., and Zhu, H. (2009). A framework for assessing the systemic risk of major financial institutions. Journal of Banking and Finance, 33:2036-49.

Huang, X., Zhou, H., and Zhu, H. (2012). Assessing the systemic risk of a heterogeneous portfolio of bbanks during the recent financial crisis. Journal of Financial Stability, 8(3):193-205.

Kapinos, P., Kishor, K. A., and Ma, J. (2017). Dynamic comovements among banks, systemic risk, and the macroeconomy. mimeo.

Kapinos, P. and Mitnik, O. A. (2016). A top-down approach to stress-testing banks. Journal of Financial Services Research, 49:229-264.

King, T., Nuxoll, D., and Yeager, T. (2006). Are the causes of bank distress changing? can researchers keep up? Federal Reserve Bank of St. Louis Review, 88:57-80.

Krainer, J. and Lopez, J. (2004). Incorporating equity market information into supervisory monitoring models. Journal of Money, Credit, and Banking, 36:1043-1067.

Krainer, J. and Lopez, J. (2008). Using securities market information for bank supervisory monitoring. International Journal of Central Banking, 4:125-164.

Meyer, P. and Pifer, H. (1970). Prediction of bank failures. Journal of Finance, 25(4):853-868.

Pettway, R. H. and Sinkey, J. (1980). Establishing on-site bank examination priorities: An earlywarning system using accounting and market information. Journal of Finance, 35(1):137-150.

Schorfheide, F. and Song, D. (2009). Real-Time Forecasting with a Mixed-Frequency VAR. Journal of Business and Economic Statistics, 33(3):366-80.

White, E. (2011). "to establish a more effective supervision of banking": How the birth of the fed altered bank supervision. National Bureau of Economic Research WP 16825. 
Table 1: Banks included in the sample

\begin{tabular}{llcc}
\hline \hline Ticker & Bank Name & Total Assets & in MIDAS? \\
\hline AXP & American Express Company & 181 & $\mathrm{~N}$ \\
BAC & Bank of America & 2,281 & $\mathrm{Y}$ \\
BK & Bank of New York Mellon & 372 & $\mathrm{~N}$ \\
BCS* & Barclays & 158 & $\mathrm{~N}$ \\
BBT & BB\&T Corporation & 2212 & $\mathrm{Y}$ \\
BBVA* & BBVA Compass Bancshares & 87 & $\mathrm{Y}$ \\
COF & Capital One Financial & 366 & $\mathrm{~N}$ \\
C & Citigroup & 1,842 & $\mathrm{Y}$ \\
CMA & Comerica Incorporated & 72 & $\mathrm{Y}$ \\
CS* & Creidt Suisse Group AG & 141 & $\mathrm{~N}$ \\
DB* & Deutsche Bank US & 148 & $\mathrm{~N}$ \\
FITB & Fifth Third Bancorp & 142 & $\mathrm{~N}$ \\
GS & Goldman Sachs Group & 917 & $\mathrm{~N}$ \\
HBAN & Huntington Bancshares Incorporated & 104 & $\mathrm{Y}$ \\
JPM & JPMorgan Chase \& Co. & 2,534 & $\mathrm{Y}$ \\
KEY & KeyCorp & 138 & $\mathrm{Y}$ \\
MTB & M\&T Bank Corporation & 119 & $\mathrm{Y}$ \\
MS & Morgan Stanley & 852 & $\mathrm{~N}$ \\
NTRS & Northern Trust Corporation & 139 & $\mathrm{Y}$ \\
PNC & PNC Financial Services Group & 381 & $\mathrm{Y}$ \\
RF & Regions Financial & 125 & $\mathrm{~N}$ \\
STT & State Street Corporation & 238 & $\mathrm{Y}$ \\
STI & Suntrust Banks & 207 & $\mathrm{Y}$ \\
TD* & TD Group US Holdings & 381 & $\mathrm{~N}$ \\
USB & U.S. Bancorp & 462 & $\mathrm{Y}$ \\
WFC & Wells Fargo \& Company & 1,952 & $\mathrm{Y}$ \\
ZION & Zion Bancorporation & 66 & $\mathrm{Y}$ \\
\hline & & & \\
\hline
\end{tabular}

Note: Total assets are in billion USD as of 2017Q4. * Indicates only U.S. assets of foreign-owned companies are reported. "In MIDAS?" indicates whether or not the bank is included in the MIDAS measure sample. 
Figure 1: Stock returns decomposition for Wells Fargo

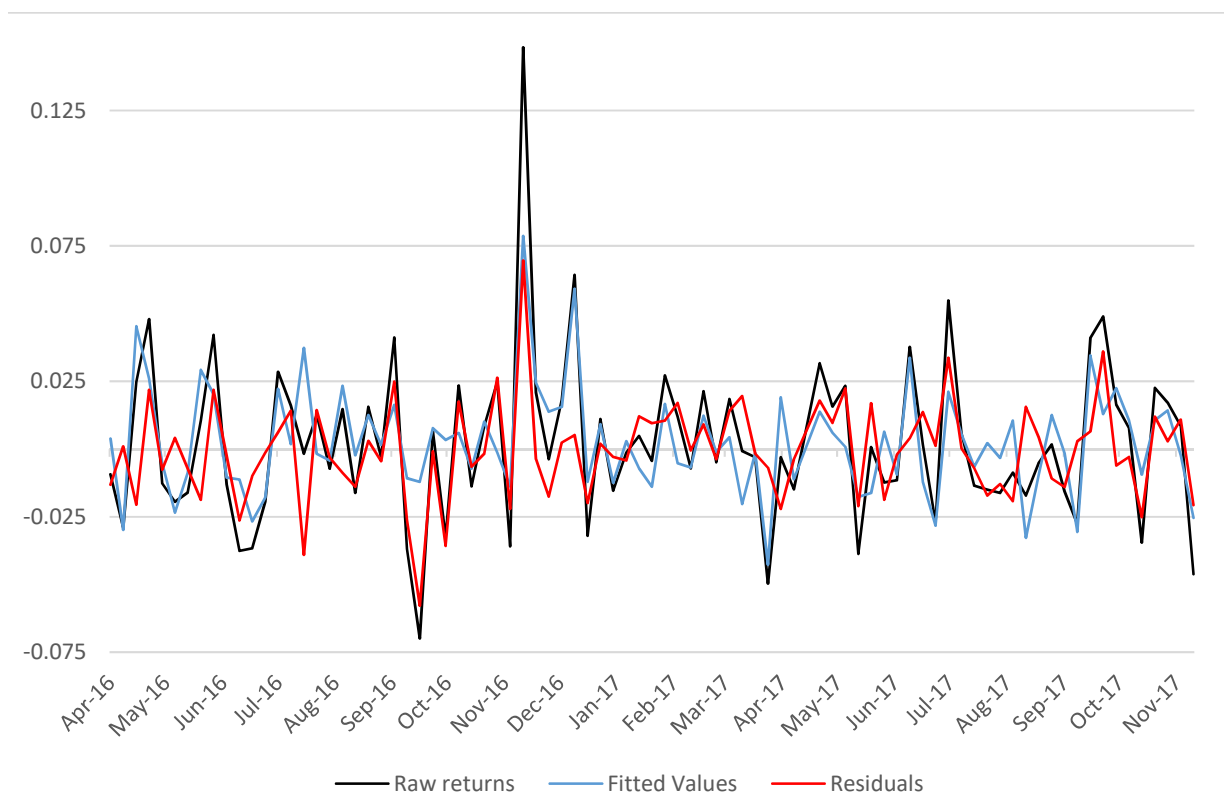

Note: Reported are weekly stock returns as well as fitted values and residuals from the CAPM regression estimated for the last 3-year rolling window. Only last 6 quarters are shown for exposition purposes.

Source: Bloomberg and authors' calculations. 
Figure 2: $R^{2}$ from rolling CAPM regression (last rolling window)

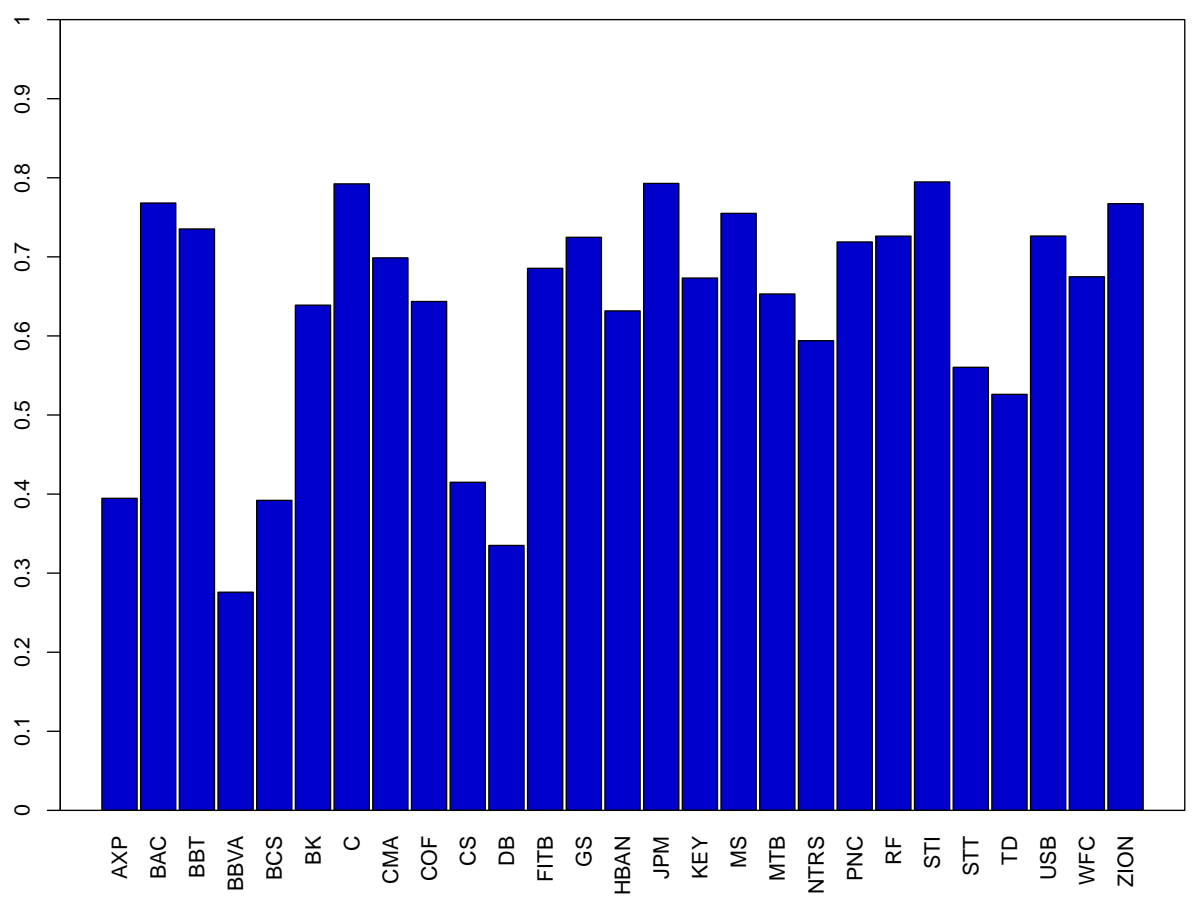

Source: Bloomberg and authors' calculations.

Figure 3: Adjacency matrix for idiosyncratic stock returns (last rolling window)

AXP BAC BBT BBVA BCS BK C CMA COF CS DB FITB GS HBAN JPM KEY MS MTB NTRS PNC RF STI STT TD USB WFC ZION $\begin{array}{lllllllllllllllllllllllllll}0.04 & 0.03 & 0.01 & 0.01 & 0.04 & 0.02 & 0.04 & 0.02 & 0.00 & 0.01 & 0.08 & 0.00 & 0.02 & 0.01 & 0.02 & 0.01 & 0.02 & 0.02 & 0.03 & 0.03 & 0.02 & 0.01 & 0.00 & 0.03 & 0.00 & 0.02 & 0.02\end{array}$

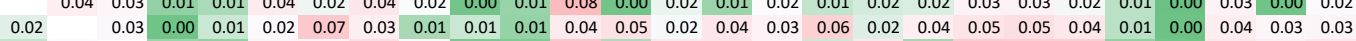
$\begin{array}{lllllllllllllllllllllllllll}0.01 & 0.02 & 0.01 & 0.01 & 0.03 & 0.03 & 0.05 & 0.02 & 0.00 & 0.00 & 0.07 & 0.01 & 0.04 & 0.05 & 0.03 & 0.01 & 0.04 & 0.01 & 0.07 & 0.07 & 0.07 & 0.01 & 0.00 & 0.04 & 0.03 & 0.04\end{array}$ \begin{tabular}{lllllll|l|l|l|l|l|l|l|l|l|l|l|l|l|l|l|l|l|l|l|l|l|l}
0.01 & 0.00 & 0.01 & 0.09 & 0.03 & 0.04 & 0.02 & 0.00 & 0.12 & 0.12 & 0.02 & 0.01 & 0.02 & 0.00 & 0.02 & 0.01 & 0.01 & 0.02 & 0.00 & 0.01 & 0.00 & 0.01 & 0.01 & 0.01 & 0.01 & 0.01
\end{tabular} $\begin{array}{llllllllllllllllllllllllllll}0.01 & 0.02 & 0.01 & 0.07 & & 0.02 & 0.02 & 0.02 & 0.00 & 0.09 & 0.10 & 0.03 & 0.01 & 0.02 & 0.01 & 0.05 & 0.01 & 0.01 & 0.02 & 0.02 & 0.04 & 0.00 & 0.03 & 0.01 & 0.02 & 0.02 & 0.02\end{array}$ $\begin{array}{lllllllllllllllllllllllllll}0.02 & 0.03 & 0.03 & 0.02 & 0.01 & & 0.04 & 0.04 & 0.01 & 0.01 & 0.01 & 0.06 & 0.02 & 0.02 & 0.02 & 0.04 & 0.03 & 0.02 & 0.04 & 0.06 & 0.07 & 0.03 & 0.04 & 0.00 & 0.03 & 0.01 & 0.04\end{array}$

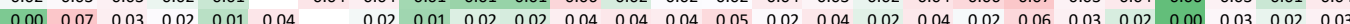
$\begin{array}{lllllllllllllllllll}0.00 & 0.00 & 0.03 & 0.01 & 0.02 & 0.03 & 0.01 & 0.01 & 0.02 & 0.00 & 0.04 & 0.02 & 0.02 & 0.00\end{array}$

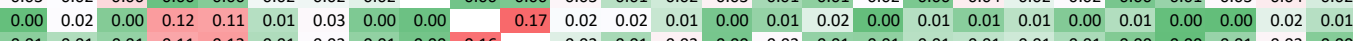

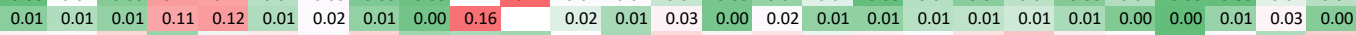
$\begin{array}{llllllllllllllllllllllllllll}0.03 & 0.03 & 0.06 & 0.01 & 0.02 & 0.04 & 0.03 & 0.06 & 0.01 & 0.01 & 0.01 & & 0.01 & 0.06 & 0.03 & 0.05 & 0.02 & 0.03 & 0.02 & 0.05 & 0.08 & 0.04 & 0.02 & 0.00 & 0.02 & 0.01 & 0.07\end{array}$

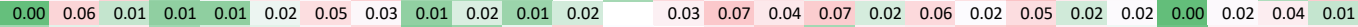
$\begin{array}{llllllllllllllllllllllllllll}0.01 & 0.02 & 0.04 & 0.01 & 0.02 & 0.02 & 0.03 & 0.06 & 0.00 & 0.01 & 0.02 & 0.07 & 0.02 & & 0.04 & 0.07 & 0.01 & 0.03 & 0.04 & 0.06 & 0.07 & 0.03 & 0.02 & 0.00 & 0.03 & 0.03 & 0.04\end{array}$ $\begin{array}{lllllllllllllllllllllllllllll}0.00 & 0.04 & 0.05 & 0.00 & 0.00 & 0.02 & 0.05 & 0.03 & 0.01 & 0.00 & 0.00 & 0.04 & 0.05 & 0.04 & & 0.04 & 0.02 & 0.04 & 0.03 & 0.04 & 0.06 & 0.04 & 0.02 & 0.00 & 0.06 & 0.05 & 0.03\end{array}$ $\begin{array}{lllllllllllllllllll}0.01 & 0.03 & 0.03 & 0.01 & 0.03 & 0.03 & 0.02 & 0.06 & 0.00 & 0.00 & 0.01 & 0.05 & 0.03 & 0.06 & 0.04 & 0.04 & 0.03\end{array}$ $\begin{array}{lllllllllllll}0.02 & 0.00 & 0.01 & 0.02 & 0.03 & 0.02 & 0.03 & 0.01 & 0.02 & 0.01 & 0.01\end{array}$ $\begin{array}{llllllllllllllllllllllllllllll}0.01 & 0.02 & 0.05 & 0.01 & 0.01 & 0.02 & 0.02 & 0.02 & 0.01 & 0.00 & 0.00 & 0.05 & 0.01 & 0.04 & 0.05 & 0.05 & 0.00 & 0.02 & 0.08 & 0.06 & 0.04 & 0.00 & 0.00 & 0.07 & 0.04 & 0.04\end{array}$ $\begin{array}{llllllllllllllllllllllllllll}0.01 & 0.04 & 0.01 & 0.01 & 0.02 & 0.05 & 0.04 & 0.05 & 0.00 & 0.01 & 0.01 & 0.03 & 0.05 & 0.05 & 0.03 & 0.07 & 0.01 & 0.02 & & 0.03 & 0.05 & 0.04 & 0.04 & 0.00 & 0.03 & 0.02 & 0.04 \\ 0.01 & 0.03 & 0.06 & 0.00 & 0.01 & 0.04 & 0.02 & 0.04 & 0.01 & 0.00 & 0.01 & 0.05 & 0.01 & 0.06 & 0.03 & 0.06 & 0.01 & 0.06 & 0.02 & & 0.06 & 0.06 & 0.01 & 0.00 & 0.07 & 0.04 & 0.03\end{array}$ $\begin{array}{llllllllllllllllllllllllllllll}0.01 & 0.03 & 0.06 & 0.00 & 0.01 & 0.04 & 0.02 & 0.04 & 0.01 & 0.00 & 0.01 & 0.05 & 0.01 & 0.06 & 0.03 & 0.06 & 0.01 & 0.06 & 0.02 & & 0.06 & 0.06 & 0.01 & 0.00 & 0.07 & 0.04 & 0.03\end{array}$ $\begin{array}{lllllllllllllllllllllllllllll}0.01 & 0.03 & 0.05 & 0.00 & 0.02 & 0.05 & 0.04 & 0.05 & 0.00 & 0.01 & 0.01 & 0.07 & 0.03 & 0.06 & 0.05 & 0.05 & 0.01 & 0.03 & 0.03 & 0.05 & & 0.05 & 0.02 & 0.00 & 0.03 & 0.02 & 0.07\end{array}$ $\begin{array}{llllllllllllllllllllllllllllllllll}0.01 & 0.04 & 0.07 & 0.00 & 0.00 & 0.03 & 0.03 & 0.05 & 0.01 & 0.00 & 0.01 & 0.05 & 0.01 & 0.04 & 0.04 & 0.05 & 0.01 & 0.03 & 0.03 & 0.07 & 0.07 & & 0.01 & 0.02 & 0.05 & 0.03 & 0.02\end{array}$ $\begin{array}{llllllllllllllllllllllllllll}0.01 & 0.02 & 0.01 & 0.01 & 0.03 & 0.06 & 0.02 & 0.03 & 0.00 & 0.01 & 0.00 & 0.05 & 0.03 & 0.04 & 0.03 & 0.02 & 0.04 & 0.01 & 0.06 & 0.03 & 0.04 & 0.01 & & 0.00 & 0.03 & 0.00 & 0.04\end{array}$ $\begin{array}{llllllllllllllllllllllllllllll}0.00 & 0.01 & 0.01 & 0.03 & 0.03 & 0.00 & 0.00 & 0.00 & 0.01 & 0.00 & 0.00 & 0.00 & 0.00 & 0.01 & 0.00 & 0.00 & 0.01 & 0.00 & 0.00 & 0.01 & 0.00 & 0.06 & 0.00 & & 0.00 & 0.00 & 0.02\end{array}$

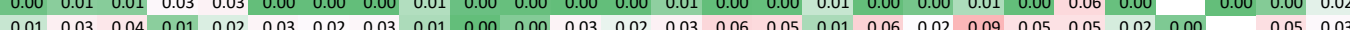
$\begin{array}{llllllllllllllllllllllllllllll}0.01 & 0.03 & 0.04 & 0.01 & 0.02 & 0.03 & 0.02 & 0.03 & 0.01 & 0.00 & 0.00 & 0.03 & 0.02 & 0.03 & 0.06 & 0.05 & 0.01 & 0.06 & 0.02 & 0.09 & 0.05 & 0.05 & 0.02 & 0.00 & 0.05 & 0.03 \\ 0.00 & 0.03 & 0.04 & 0.01 & 0.02 & 0.02 & 0.02 & 0.02 & 0.02 & 0.01 & 0.02 & 0.02 & 0.03 & 0.04 & 0.07 & 0.05 & 0.01 & 0.04 & 0.02 & 0.06 & 0.04 & 0.03 & 0.00 & 0.01 & 0.06 & & 0.02\end{array}$ $\begin{array}{lllllllllllllllllllllllllll}0.00 & 0.03 & 0.04 & 0.01 & 0.02 & 0.02 & 0.02 & 0.02 & 0.02 & 0.01 & 0.02 & 0.02 & 0.03 & 0.04 & 0.07 & 0.05 & 0.01 & 0.04 & 0.02 & 0.06 & 0.04 & 0.03 & 0.00 & 0.01 & 0.06 & & 0.02 \\ 0.01 & 0.04 & 0.00 & 0.02 & 0.04 & 0.03 & 0.09 & 0.00 & 0.01 & 0.00 & 0.09 & 0.01 & 0.04 & 0.04 & 0.03 & 0.01 & 0.03 & 0.03 & 0.03 & 0.10 & 0.02 & 0.03 & 0.00 & 0.03 & 0.02 & \end{array}$

Note: Reported are coefficients from variance decomposition of the 1-quarter-ahead forecast error. Diagonal is removed. Element $a_{i j}$ shows the share of contribution of bank $j$ to the forecast error variance of bank $i$.

Source: Bloomberg and authors' calculations. 
Figure 4: Density of the network of idiosyncratic stock returns

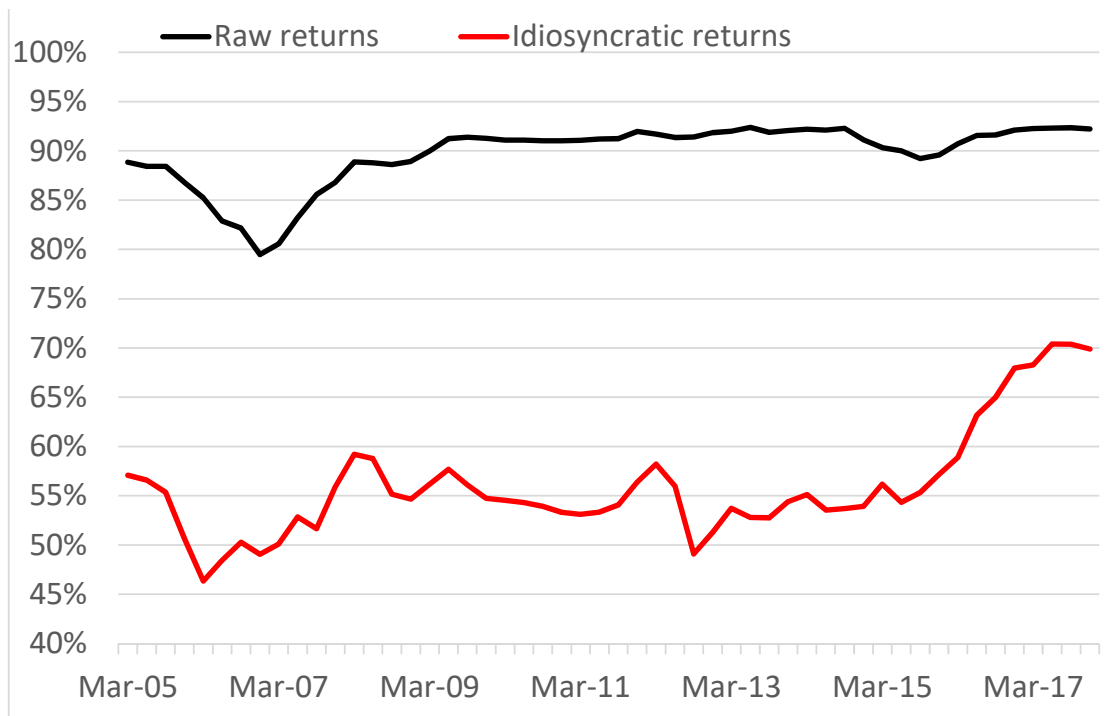

Note: Network density is computed as average share of 1-quarter-ahead forecast error variance explained by other banks across all banks.

Source: Bloomberg and authors' calculations. 
Figure 5: Network impact by bank business model

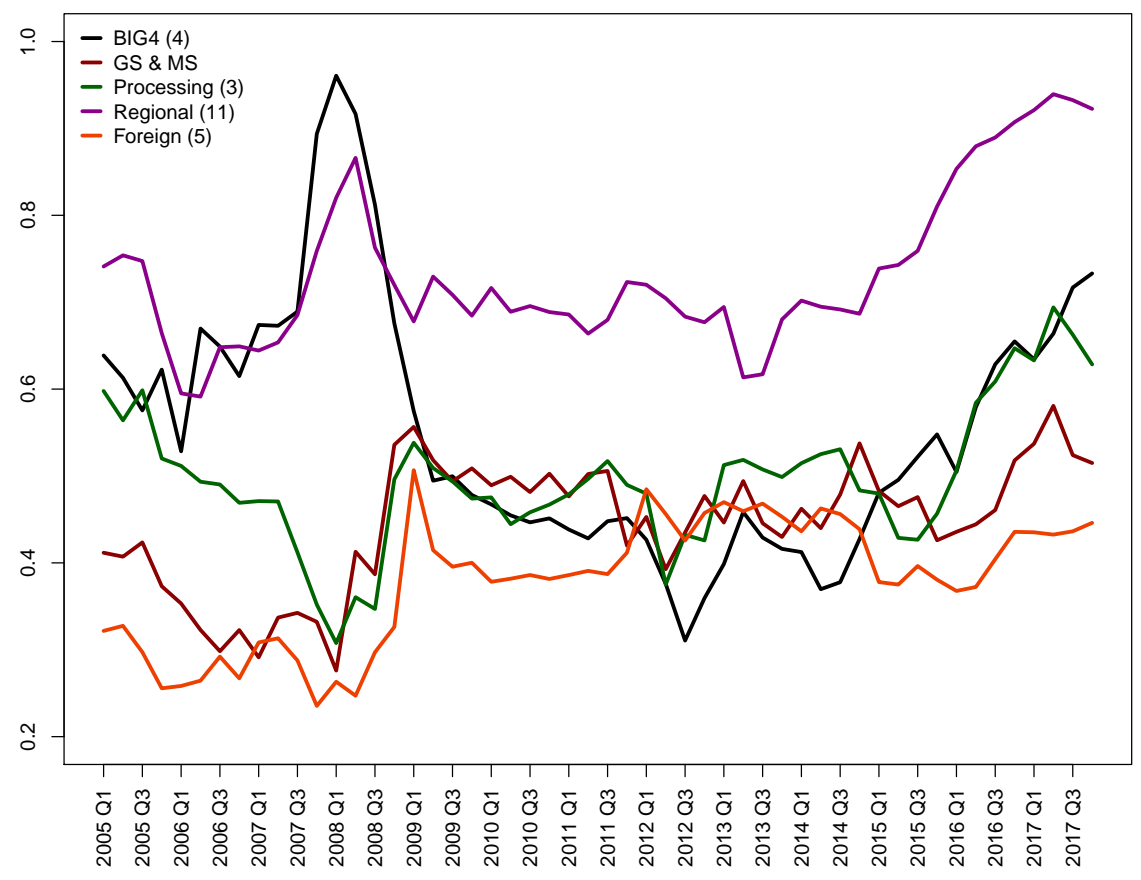

Note: Network impact is the sum across banks of the share of the 1-quarter-ahead forecast error variance explained by a given bank. Simple average of this measure for each bank group is reported.

Source: Bloomberg and authors' calculations. 
Figure 6: Network vulnerability by bank business model

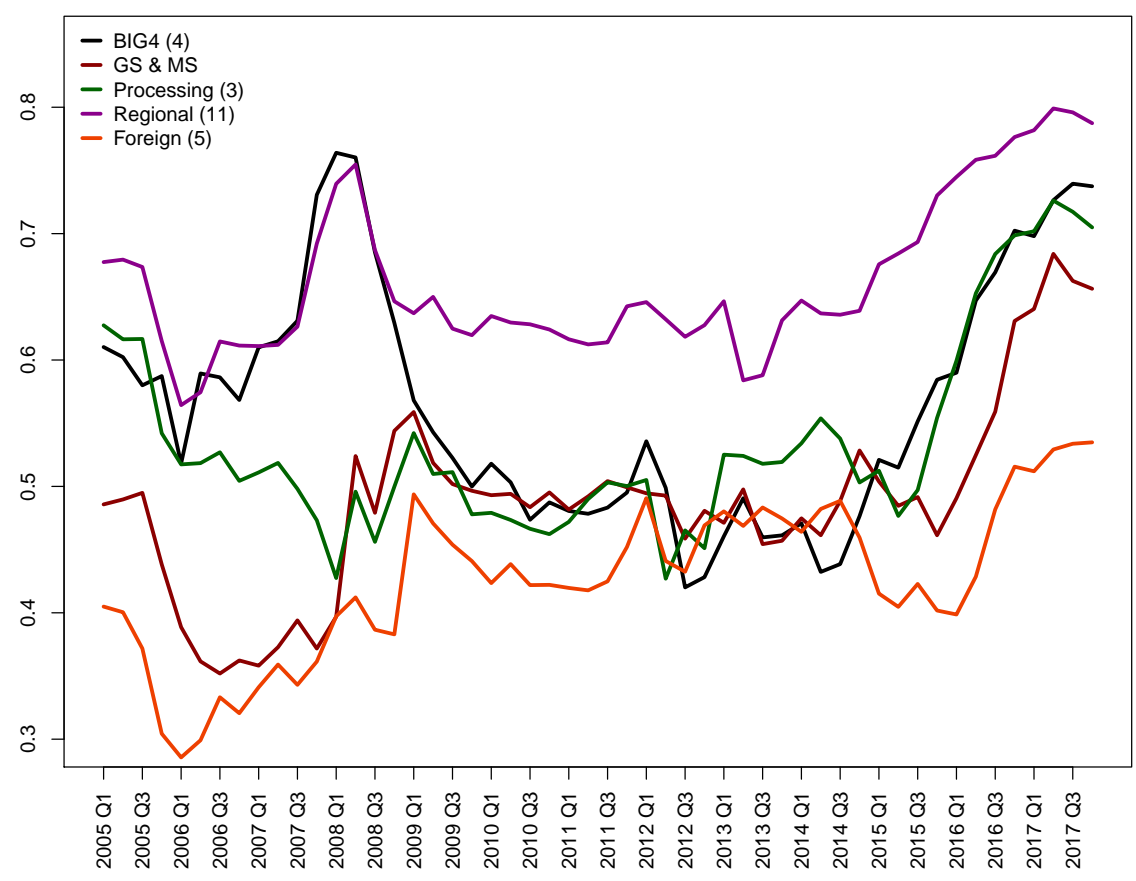

Note: Network vulnerability is the share of the 1-quarter-ahead forecast error variance of a given bank explained by other banks. Simple average of this measure for each bank group is reported. Source: Bloomberg and authors' calculations. 
Figure 7: Comparison of idiosyncratic returns connectedness measure with other measures

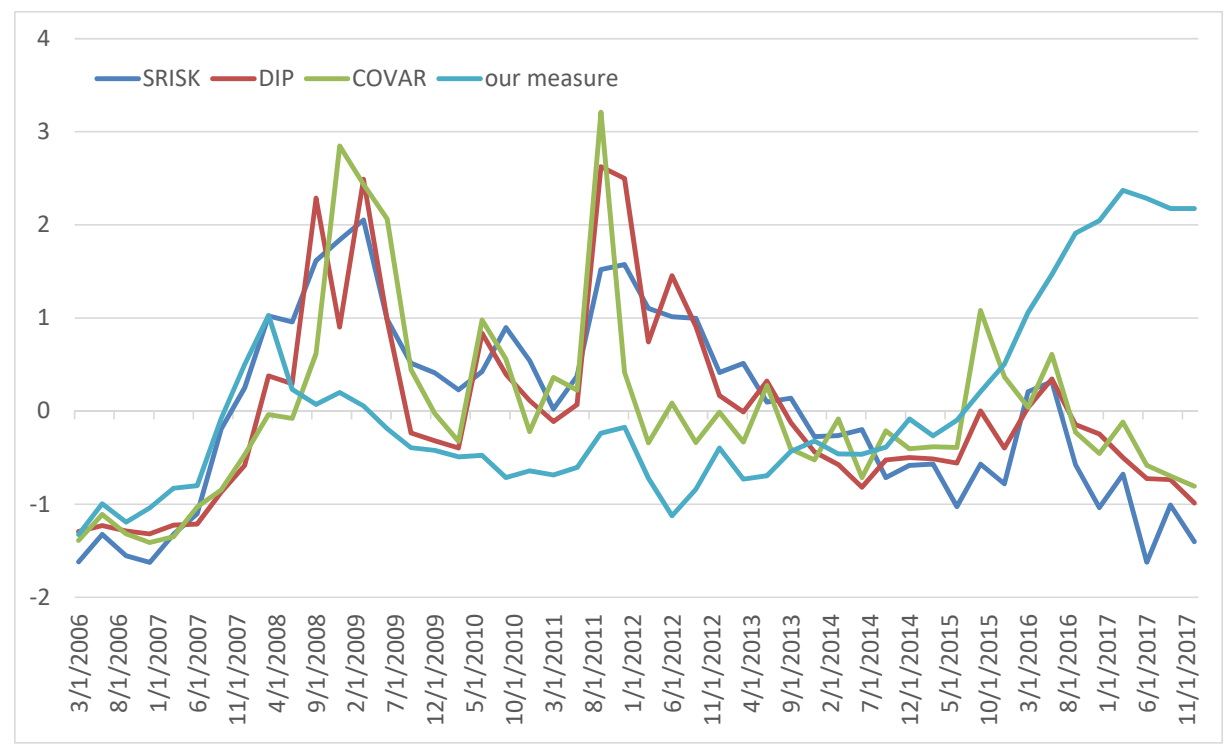

Note: All measures are for the following 11 banks: BAC, BCS, BK, C, CS, DB, GS, JPM, MS, STT, WFC . Simple averages across banks. All measures are normalized and standardized for comparison.

Source: Bloomberg and authors' calculations.

Figure 8: Network impact of selected bank groups around crisis time

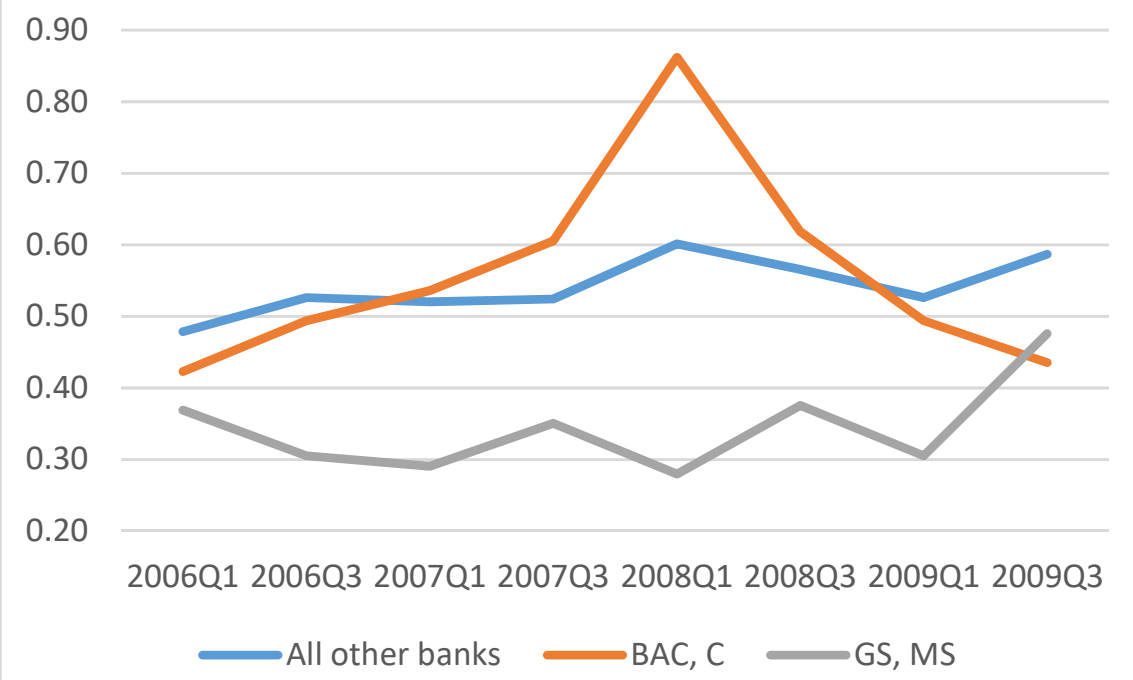

Note: Network impact is the sum across banks of the share of the 1-quarter-ahead forecast error variance explained by a given bank. Simple average of this measure for each bank group is reported.

Source: Bloomberg and authors' calculations. 
Figure 9: ROA decomposition for Wells Fargo

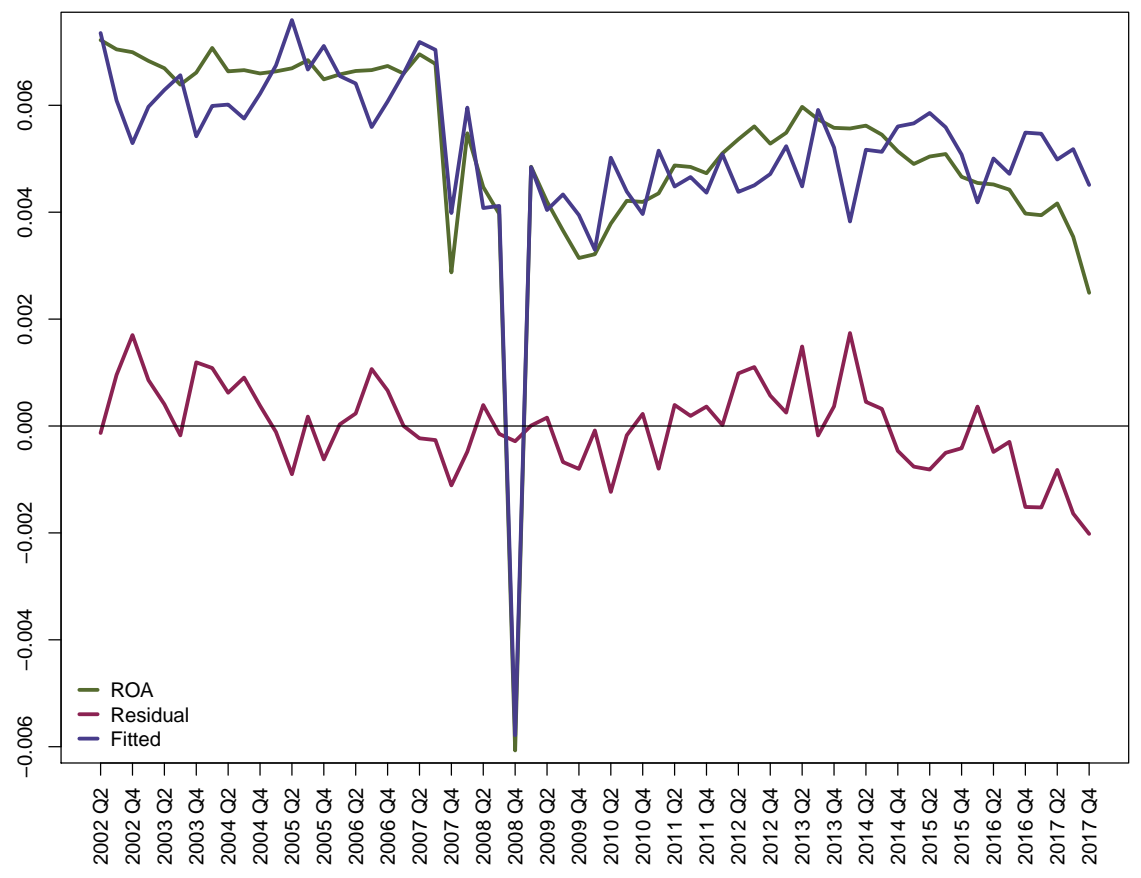

Note: Reported are quarterly return on assets as well as fitted values and residuals from the MIDAS regression estimated for the full sample period as shown.

Source: Bloomberg and authors' calculations. 
Figure 10: $R^{2}$ from MIDAS regression

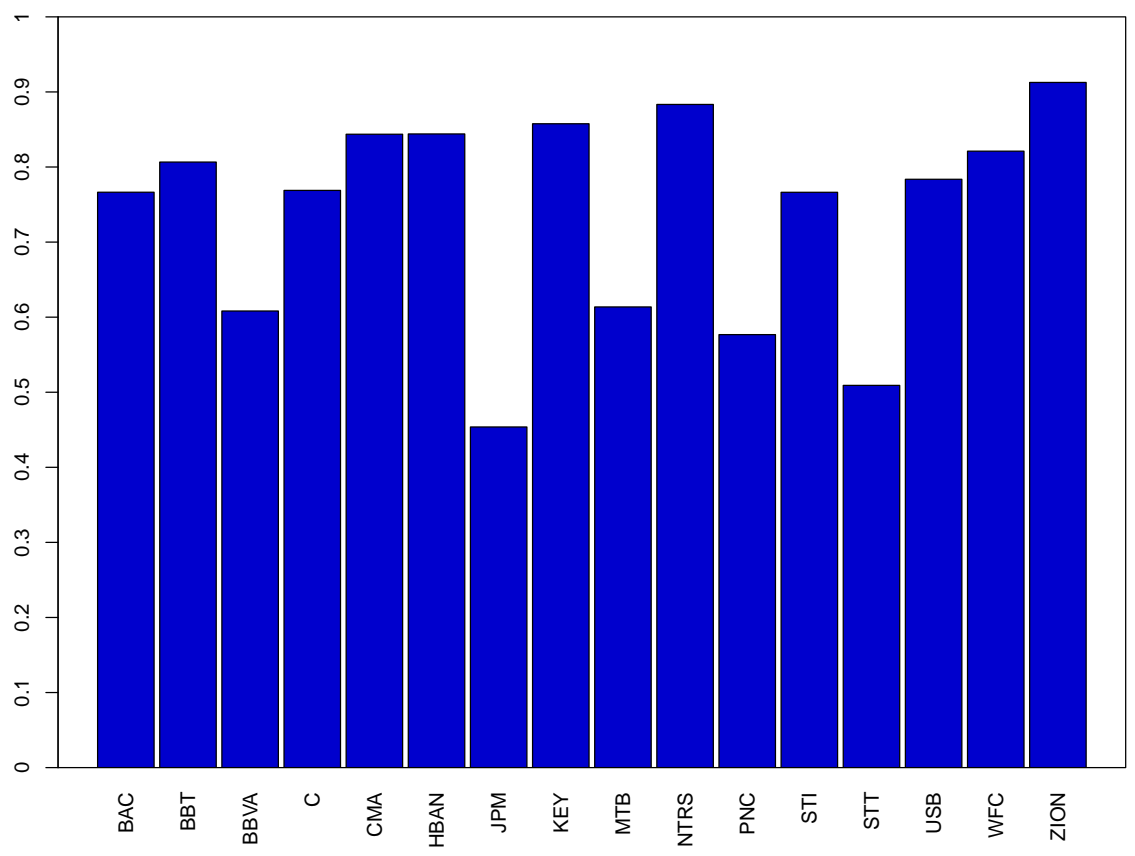

Source: Bloomberg and authors' calculations.

Figure 11: Adjacency matrix for observed ROA component (last rolling window)

\begin{tabular}{|c|c|c|c|c|c|c|c|c|c|c|c|c|c|c|c|}
\hline & BAC & BBT & BBVA & & CMA & HBAN & PPM & KEY & МТВ & NTRS & PNC & STI & STT & USB & WFC \\
\hline BBT & 0.70 & & & & & & & & & & & & & & \\
\hline BVA & 0.08 & 0.45 & & & & & & & & & & & & & \\
\hline & 0.57 & 0.75 & 0.67 & & & & & & & & & & & & \\
\hline MA & 0.51 & 0.79 & 0.43 & 0.79 & & & & & & & & & & & \\
\hline ABAN & 0.32 & 0.04 & 0.06 & 0.31 & 0.28 & & & & & & & & & & \\
\hline PM & 0.00 & 0.01 & 0.33 & 0.23 & 0.13 & 0.06 & & & & & & & & & \\
\hline KEY & 0.43 & 0.63 & 0.29 & 0.77 & 0.78 & 0.22 & 0.00 & & & & & & & & \\
\hline MTB & 0.50 & 0.51 & 0.23 & 0.58 & 0.60 & 0.63 & 0.00 & 0.71 & & & & & & & \\
\hline NTRS & 0.18 & 0.00 & 0.00 & 0.14 & 0.00 & 0.60 & 0.00 & 0.03 & 0.10 & & & & & & \\
\hline PNC & 0.81 & 0.71 & 0.17 & 0.68 & 0.55 & 0.29 & 0.09 & 0.49 & 0.46 & 0.20 & & & & & \\
\hline STI & 0.55 & 0.24 & 0.00 & 0.09 & 0.08 & 0.30 & 0.00 & 0.34 & 0.61 & 0.08 & 0.21 & & & & \\
\hline STT & 0.54 & 0.20 & 0.00 & 0.26 & 0.29 & 0.21 & 0.00 & 0.29 & 0.21 & 0.25 & 0.36 & 0.13 & & & \\
\hline USB & 0.77 & 0.73 & 0.33 & 0.63 & 0.62 & 0.40 & 0.00 & 0.56 & 0.72 & 0.13 & 0.51 & 0.57 & 0.41 & & \\
\hline WFC & 0.41 & 0.51 & 0.50 & 0.55 & 0.33 & 0.00 & 0.00 & 0.38 & 0.40 & 0.00 & 0.20 & 0.37 & 0.11 & 0.75 & \\
\hline ZION & 0.56 & 0.40 & 0.29 & 0.58 & 0.69 & 0.72 & 0.02 & 0.57 & 0.69 & 0.23 & 0.45 & 0.32 & 0.55 & 0.56 & 0.10 \\
\hline
\end{tabular}

Note: Reported are correlation coefficients (with negative numbers replaced with zeros) for the fitted values from ROA MIDAS regression. Correlations are computed for the last 16 quarters of the sample.

Source: Bloomberg and authors' calculations. 
Figure 12: Adjacency matrix for unobserved ROA component (last rolling window)

\begin{tabular}{|c|c|c|c|c|c|c|c|c|c|c|c|c|c|c|c|}
\hline & BAC & BBT & BBVA & C & $\mathrm{CMA}$ & HBAN & PM & KEY & MTB & NTRS & PNC & STI & STT & USB & WFC \\
\hline BBT & 0.40 & & & & & & & & & & & & & & \\
\hline BBVA & 0.12 & 0.21 & & & & & & & & & & & & & \\
\hline C & 0.17 & 0.33 & 0.68 & & & & & & & & & & & & \\
\hline CMA & 0.38 & 0.12 & 0.18 & 0.24 & & & & & & & & & & & \\
\hline HBAN & 0.29 & 0.10 & 0.06 & 0.23 & 0.73 & & & & & & & & & & \\
\hline JPM & 0.10 & 0.00 & 0.17 & 0.25 & 0.22 & 0.00 & & & & & & & & & \\
\hline KEY & 0.39 & 0.55 & 0.16 & 0.60 & 0.43 & 0.46 & 0.14 & & & & & & & & \\
\hline MTB & 0.35 & 0.42 & 0.26 & 0.34 & 0.69 & 0.61 & 0.13 & 0.64 & & & & & & & \\
\hline NTRS & 0.01 & 0.00 & 0.02 & 0.08 & 0.36 & 0.49 & 0.00 & 0.00 & 0.14 & & & & & & \\
\hline PNC & 0.18 & 0.30 & 0.00 & 0.36 & 0.00 & 0.37 & 0.00 & 0.67 & 0.20 & 0.00 & & & & & \\
\hline STI & 0.32 & 0.44 & 0.00 & 0.01 & 0.55 & 0.35 & 0.00 & 0.54 & 0.64 & 0.00 & 0.24 & & & & \\
\hline STT & 0.27 & 0.59 & 0.00 & 0.00 & 0.26 & 0.46 & 0.00 & 0.41 & 0.41 & 0.00 & 0.29 & 0.51 & & & \\
\hline USB & 0.34 & 0.59 & 0.00 & 0.41 & 0.17 & 0.39 & 0.00 & 0.80 & 0.31 & 0.00 & 0.83 & 0.53 & 0.63 & & \\
\hline WFC & 0.13 & 0.55 & 0.26 & 0.49 & 0.00 & 0.11 & 0.00 & 0.63 & 0.14 & 0.00 & 0.79 & 0.25 & 0.42 & 0.86 & \\
\hline ZION & 0.44 & 0.53 & 0.14 & 0.20 & 0.65 & 0.59 & 0.00 & 0.41 & 0.49 & 0.00 & 0.10 & 0.50 & 0.69 & 0.47 & 0.25 \\
\hline
\end{tabular}

Note: Reported are correlation coefficients (with negative numbers replaced with zeros) for the residuals from ROA MIDAS regression. Correlations are computed for the last 16 quarters of the sample.

Source: Bloomberg and authors' calculations. 
Figure 13: Connectedness of the observed ROA component — four largest banks

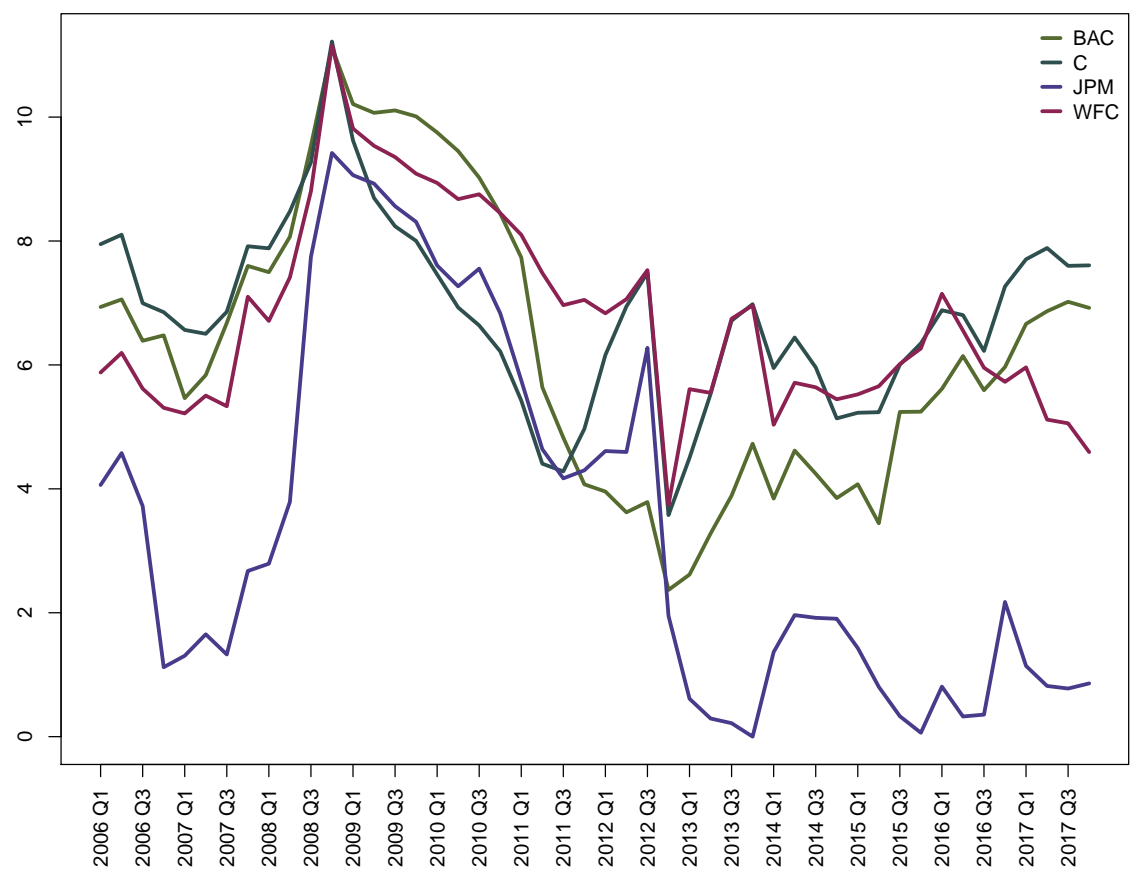

Note: Reported are average correlation coefficients (with negative numbers replaced with zeros) for the fitted values from ROA MIDAS regression for each of the four banks with all other banks in the network.

Source: Bloomberg and authors' calculations. 
Figure 14: Connectedness of the unobserved ROA component — four largest banks

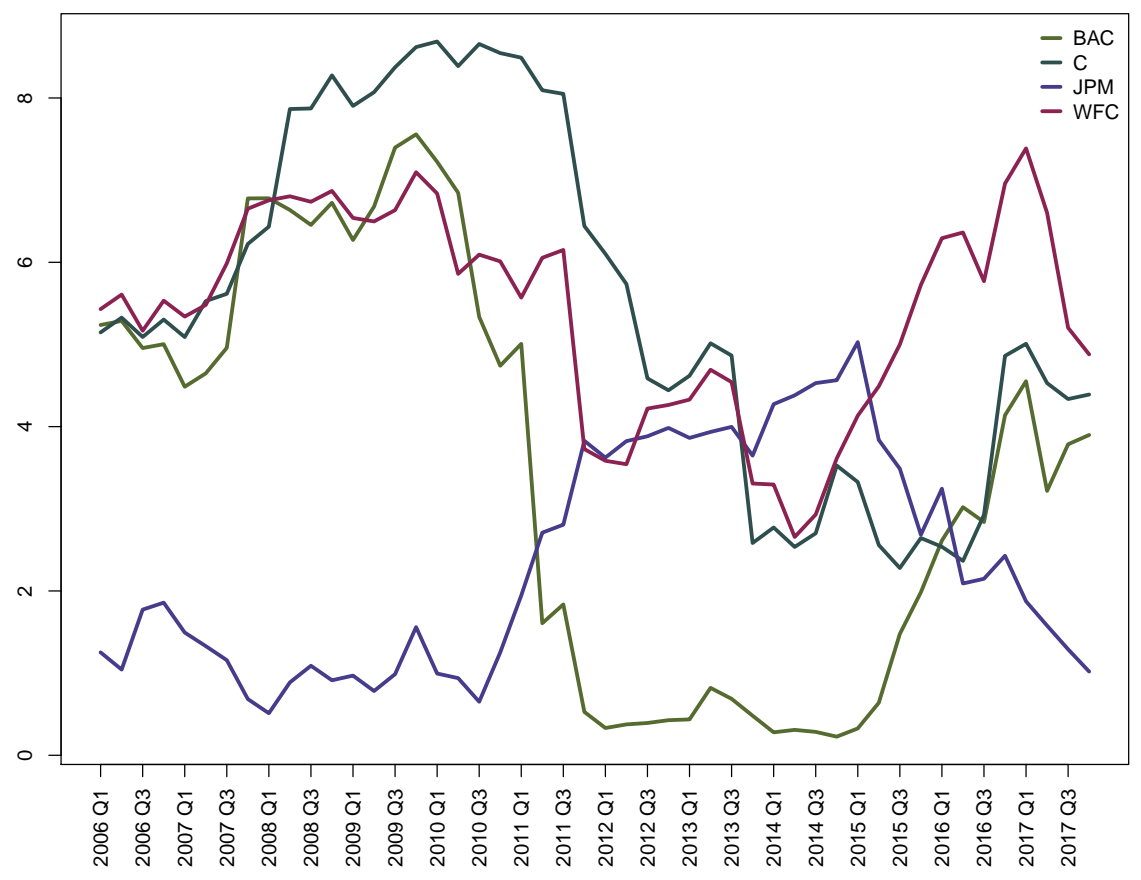

Note: Reported are average correlation coefficients (with negative numbers replaced with zeros) for the residuals from ROA MIDAS regression for each of the four banks with all other banks in the network.

Source: Bloomberg and authors' calculations. 
Figure 15: Network density for ROA and its decomposition

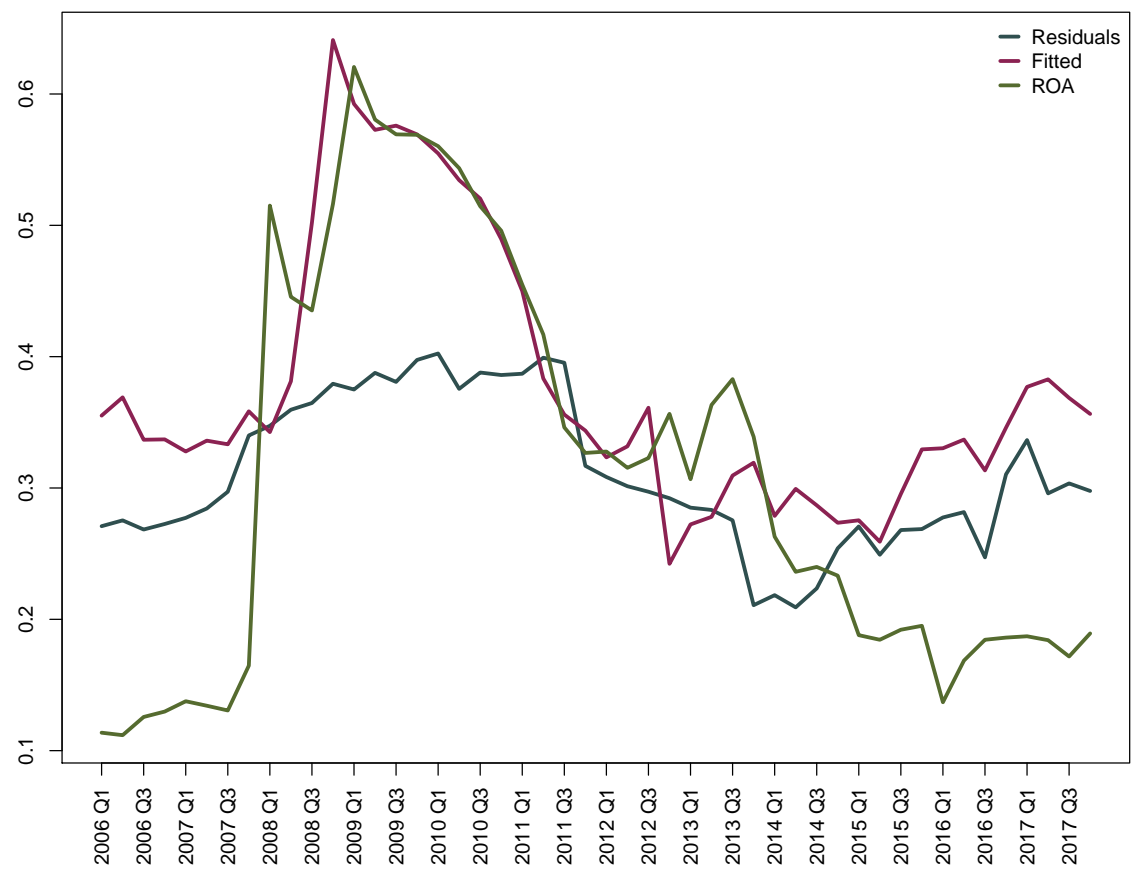

Note: Reported are average correlation coefficients (with negative numbers replaced with zeros) for ROA as well as fitted values and residuals from ROA MIDAS regression.

Source: Bloomberg and authors' calculations. 
Figure 16: Connectedness between observed and unobserved ROA components

\begin{tabular}{|c|c|c|c|c|c|c|c|c|c|c|c|c|c|c|c|c|}
\hline ted & BAC & BBT & BBVA & C & CMA & HBAN & JPM & KEY & MTB & NTRS & PNC & STI & STT & USB & WFC & ZION \\
\hline BAC & 0.00 & 0.00 & 0.00 & 0.00 & 0.00 & 0.00 & 0.45 & 0.00 & 0.00 & 0.16 & 0.00 & 0.00 & 0.00 & 0.00 & 0.00 & 0.00 \\
\hline BBT & 0.00 & 0.00 & 0.00 & 0.00 & 0.00 & 0.00 & 0.12 & 0.00 & 0.00 & 0.31 & 0.00 & 0.00 & 0.00 & 0.00 & 0.00 & 0.00 \\
\hline BBVA & 0.00 & 0.00 & 0.00 & 0.00 & 0.00 & 0.00 & 0.00 & 0.00 & 0.00 & 0.04 & 0.00 & 0.22 & 0.21 & 0.01 & 0.00 & 0.00 \\
\hline C & 0.00 & 0.00 & 0.00 & 0.00 & 0.00 & 0.00 & 0.00 & 0.00 & 0.00 & 0.05 & 0.00 & 0.00 & 0.00 & 0.00 & 0.00 & 0.00 \\
\hline CMA & 0.00 & 0.00 & 0.00 & 0.00 & 0.00 & 0.00 & 0.00 & 0.00 & 0.00 & 0.16 & 0.00 & 0.00 & 0.00 & 0.00 & 0.00 & 0.00 \\
\hline HBAN & 0.00 & 0.00 & 0.00 & 0.00 & 0.00 & 0.00 & 0.00 & 0.00 & 0.00 & 0.00 & 0.00 & 0.00 & 0.00 & 0.00 & 0.00 & 0.00 \\
\hline JPM & 0.00 & 0.26 & 0.00 & 0.00 & 0.02 & 0.03 & 0.00 & 0.00 & 0.00 & 0.11 & 0.00 & 0.34 & 0.58 & 0.18 & 0.03 & 0.19 \\
\hline KEY & 0.00 & 0.00 & 0.00 & 0.00 & 0.00 & 0.00 & 0.00 & 0.00 & 0.00 & 0.09 & 0.00 & 0.00 & 0.00 & 0.00 & 0.00 & 0.00 \\
\hline MTB & 0.00 & 0.00 & 0.00 & 0.00 & 0.00 & 0.00 & 0.05 & 0.00 & 0.00 & 0.04 & 0.00 & 0.00 & 0.00 & 0.00 & 0.00 & 0.00 \\
\hline ITRS & 0.01 & 0.34 & 0.00 & 0.00 & 0.00 & 0.00 & 0.24 & 0.00 & 0.00 & 0.00 & 0.00 & .00 & .00 & .00 & 0.00 & 0.00 \\
\hline PNC & 0.00 & 0.00 & 0.00 & 0.00 & 0.06 & 0.00 & 0.33 & 0.00 & 0.00 & 0.10 & 0.00 & 0.00 & 0.00 & 0.00 & 0.00 & 0.00 \\
\hline STI & 0.00 & 0.00 & 0.20 & 0.09 & 0.00 & 0.00 & 0.28 & 0.00 & 0.00 & 0.16 & 0.00 & 0.00 & 0.00 & 0.00 & 0.00 & 0.00 \\
\hline STT & 0.00 & 0.00 & 0.07 & 0.00 & 0.17 & 0.00 & 0.59 & 0.00 & 0.08 & 0.00 & 0.00 & 0.00 & 0.00 & 0.00 & 0.00 & 0.00 \\
\hline USB & 0.00 & 0.00 & 0.00 & 0.00 & 0.00 & 0.00 & 0.30 & 0.00 & 0.00 & 0.15 & 0.00 & 0.00 & 0.00 & 0.00 & 0.00 & 0.00 \\
\hline WFC & 0.00 & 0.00 & 0.00 & 0.00 & 0.00 & 0.04 & 0.06 & 0.00 & 0.00 & 0.36 & 0.00 & 0.00 & 0.00 & 0.00 & 0.00 & 0.00 \\
\hline ION & 0.00 & 0.00 & 0.00 & 0.00 & 0.00 & 0.00 & 0.08 & 0.00 & 0.00 & 0.00 & 0.00 & 0.00 & 0.00 & 0.00 & 0.00 & 0.00 \\
\hline
\end{tabular}

Note: Reported are correlation coefficients (with negative numbers replaced with zeros) between fitted values and residuals from ROA MIDAS regression.

Source: Bloomberg and authors' calculations. 
Figure 17: Density of the subcomponents of the network that includes both observed and unobserved components of ROA for each bank

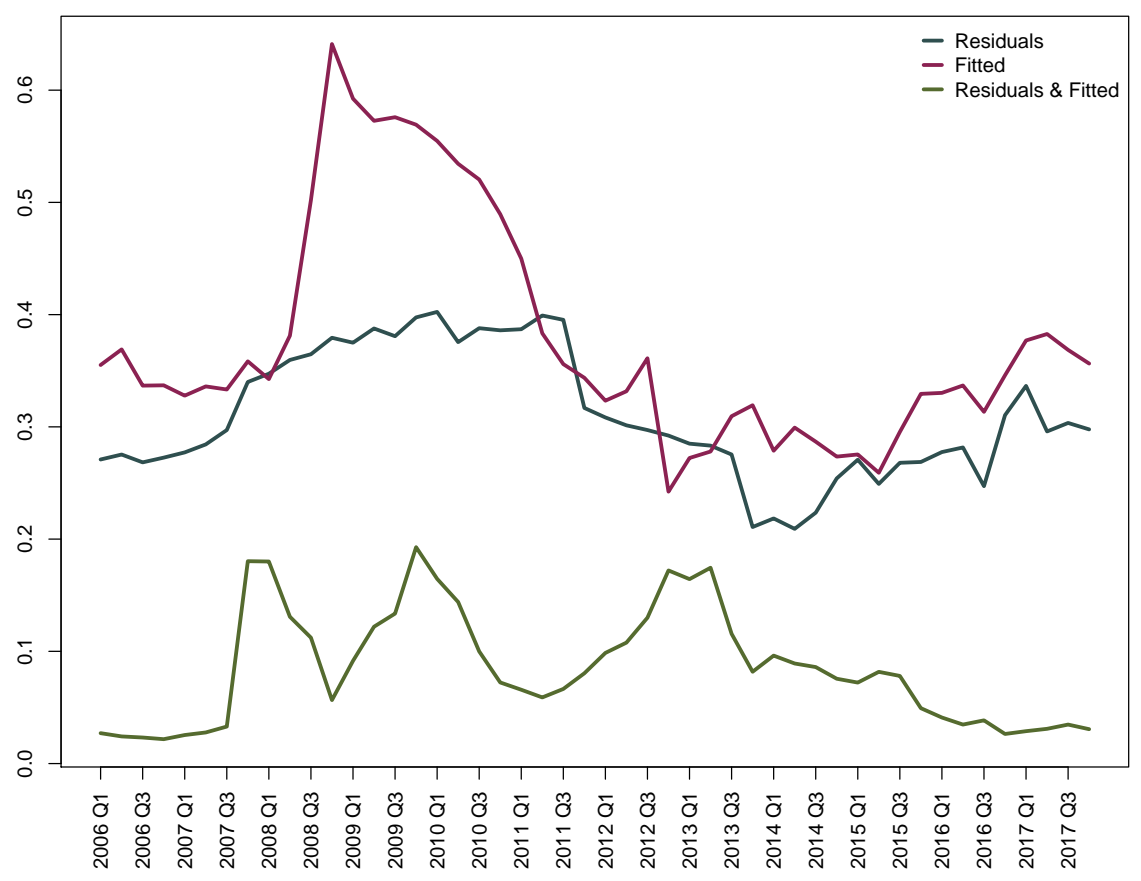

Note: Reported are average correlation coefficients (with negative numbers replaced with zeros) for fitted values and residuals as well as between fitted values and residuals from ROA MIDAS regression.

Source: Bloomberg and authors' calculations. 
Figure A1. Coefficients from rolling CAPM regressions.

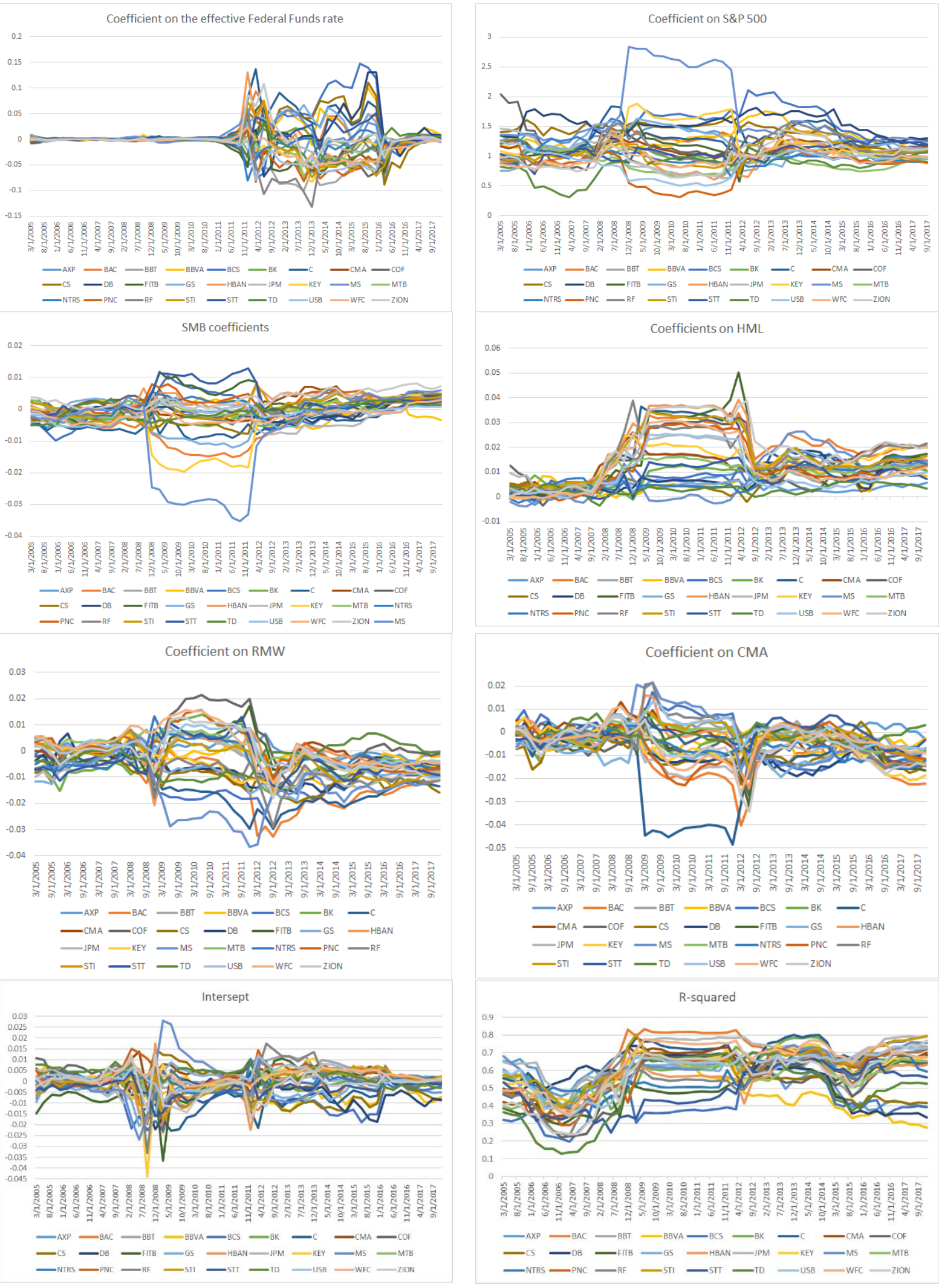


Figure A2. Measures of impact and vulnerability based on CAPM regression -4 largest banks

Impact:

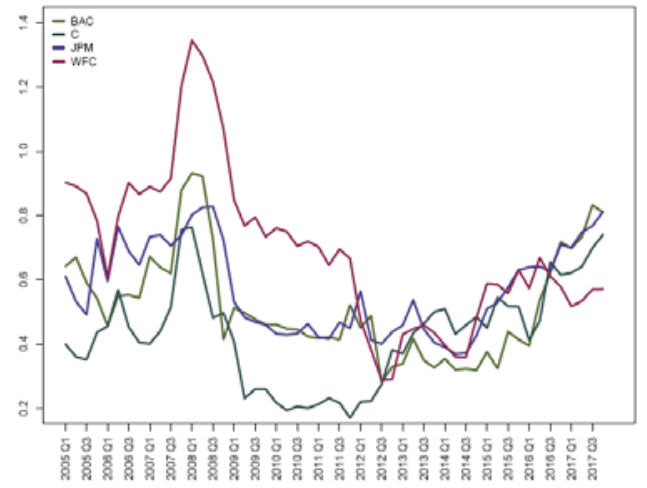

Vulnerability:

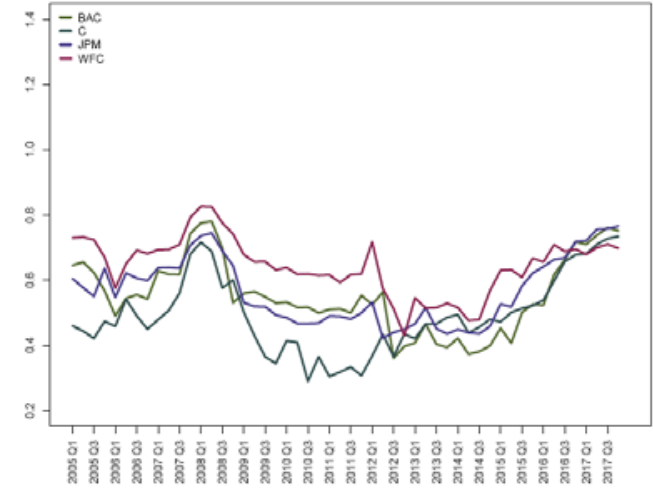

Figure A3. Coefficients MIDAS regression

Panel A. Across banks on quarterly variables with 2-s.e. bands
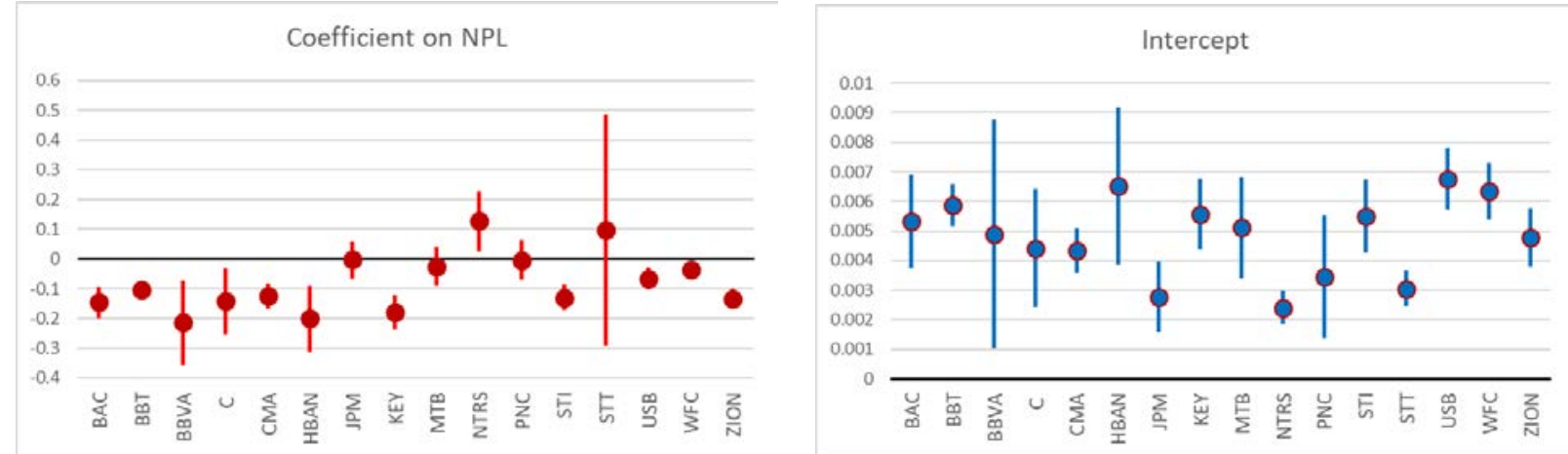

Panel B. Across banks and weekly lags
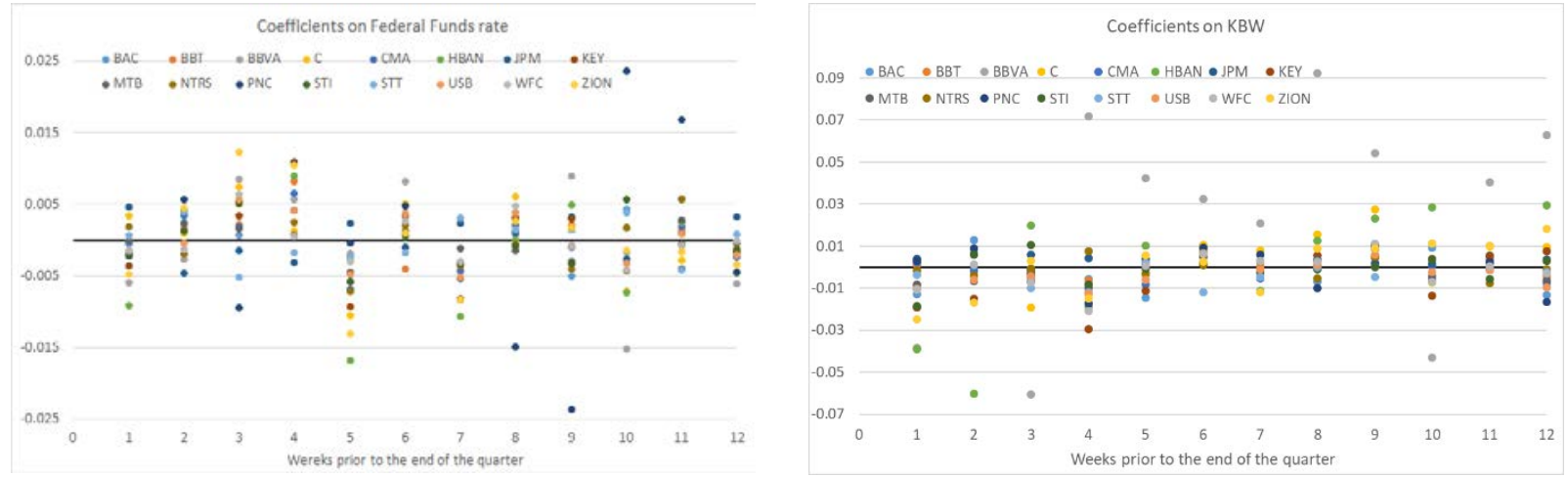